Please do not remove this page

RMIT

UNIVERSITY

\title{
Preparation of a soft and interconnected macroporous hydroxypropyl cellulose methacrylate scaffold for adipose tissue engineering
}

Hoo, Siew; Loh, Qiu; Yue, Zhilian; Fu, Jing; Tan, Timothy; Choong, Cleo; Chan, Peggy

https://researchrepository.rmit.edu.au/esploro/outputs/9921859697101341/filesAndLinks?institution=61RMIT_INST\&index=null

Hoo, S., Loh, Q., Yue, Z., Fu, J., Tan, T., Choong, C., \& Chan, P. (2013). Preparation of a soft and interconnected macroporous hydroxypropyl cellulose methacrylate scaffold for adipose tissue engineering. Journal of Materials Chemistry B, 1(24), 3107-3117. https://doi.org/10.1039/c3tb00446e Document Version: Accepted Manuscript

Published Version: https://doi.org/10.1039/c3tb00446e

Repository homepage: https://researchrepository.rmit.edu.au

(c) The Royal Society of Chemistry 2013

Downloaded On 2023/04/26 21:26:27 +1000 
Thank you for downloading this document from the RMIT Research Repository.

The RMIT Research Repository is an open access database showcasing the research outputs of RMIT University researchers.

RMIT Research Repository: http://researchbank.rmit.edu.au/

\section{Citation:}

Hoo, S, Loh, Q, Yue, Z, Fu, J, Tan, T, Choong, C and Chan, P 2013, 'Preparation of a soft and interconnected macroporous hydroxypropyl cellulose methacrylate scaffold for adipose tissue engineering', Journal of Materials Chemistry B, vol. 1, no. 24, pp. 3107-3117.

See this record in the RMIT Research Repository at:

https://researchbank.rmit.edu.au/view/rmit:26199

Version: Accepted Manuscript

Copyright Statement: (c) The Royal Society of Chemistry 2013

Link to Published Version:

http://dx.doi.org/10.1039/c3tb00446e 


\section{RSCPublishing Journalof}

\section{Preparation of soft and interconnected macroporous hydroxypropylcellulose methacrylate scaffold for adipose tissue engineering}

\begin{tabular}{|r|l|}
\hline Journal: & Journal of Materials Chemistry B \\
\hline Manuscript ID: & TB-ART-11-2012-000446.R2 \\
\hline Article Type: & Paper \\
\hline Date Submitted by the Author: & $\mathrm{n}$ /a \\
\hline Complete List of Authors: & $\begin{array}{l}\text { Hoo, Siew Pei; RMIT University, Chemistry } \\
\text { Loh, Qiu Li; Nanyang Technological University, School of Materials Science } \\
\text { \& Engineering } \\
\text { Yue, Zhilian; RMIT University, Chemistry } \\
\text { Fu, Jing; Monash University, Department of Mechanical \& Aerospace } \\
\text { Engineering } \\
\text { Tan, Timothy Thatt Yang; Nanyang Technological University, School of } \\
\text { Chemical and Biomedical Engineering } \\
\text { Choong, Cleo; Nanyang Technological University, Materials Science } \\
\text { Chan, Peggy; RMIT University, }\end{array}$ \\
\hline
\end{tabular}




\title{
Preparation of soft and interconnected macroporous hydroxypropylcellulose methacrylate scaffold for adipose tissue engineering
}

\author{
Siew Pei Hoo ${ }^{\mathrm{a}, \mathrm{b}, \mathrm{c}}$, Qiu Li Loh ${ }^{\mathrm{d}}$, Zhilian Yue ${ }^{\mathrm{e}}$, Jing Fü, Timothy T.Y.Tan ${ }^{\mathrm{g}}$, Cleo Choong* ${ }^{\text {d }}$, Peggy P.Y. \\ ${ }_{5}$ Chan*b,c \\ Received (in $X X X, X X X)$ th $X X X X X X X X X 20 X X$, Accepted $X$ th $X X X X X X X X X 20 X X$ \\ DOI: $10.1039 / \mathbf{b 0 0 0 0 0 0 x}$
}

This study describes the preparation and characterization of a biodegradable 3D hydrogel constructed from hydroxypropyl cellulose (HPC), modified with bifunctional methacrylic anhydride (MA) to form 10 hydroxpropyl cellulose methacrylate (HPC-MA), for adipose tissue engineering applications. The hydrogels were prepared from three different concentrations ( $10 \mathrm{wt} \%, 15 \mathrm{wt} \%$ and $20 \mathrm{wt} \%$ ) of HPC-MA with 0.35 degree of substitution. HPC-MA hydrogel scaffolds with open biphasic feature were prepared by exploiting the thermal responsive phase behavior of HPC and temperature mediated phase separation of HPC-MA. The resulting scaffolds exhibited pore size ranging from 30 to $300 \mu \mathrm{m}$ and interconnected ${ }_{15}$ porosity of $\sim 90 \%$. The swelling ratio (SR) and storage modulus of HPC-MA scaffolds were in the range of 12.94 - to 35.83 and 0.75 - to $4.28 \mathrm{kPa}$, respectively. The swelling ratio and storage modulus suggested that the scaffold exhibits high water retention, allowing medium exchange during cell culturing and suitable for adipose tissues regeneration. The HPC-MA scaffolds were found to be biocompatible to human adipose-derived stem cells (ASCs). ASCs were successfully differentiated into the adipocytes 20 inside the scaffolds, and therefore demonstrated the potential application of these HPC-MA scaffolds for adipose tissue engineering.

\section{Introduction}

Currently, there is a need for transplantable and functional adipose tissue to restore lost or damaged tissue due to post25 traumatic loss, lipoatrophy, tumor removal or congenital defects ${ }^{1-}$ 3. A scaffold-based tissue engineering approach is a promising alternative to current autologous fat grafts as it addresses the issue of donor site morbidity as well as other complications associated with fat graft transfers including fat necrosis and 30 volume reduction over time ${ }^{4}$. In general, an ideal scaffold for adipose tissue application should: (1) be constructed from materials with controlled biodegradability or bioresorbability so that new adipose tissues will eventually replace the scaffold, (2) possess an extensive network of interconnecting pores to promote 35 nutrient and waste exchange, (3) provide appropriate surface chemistry to facilitate cellular attachment, differentiation and proliferation, (4) be easily fabricated into a variety of shapes and sizes, (5) mimics the soft and elastic texture of native tissues, and (6) provides appropriate mechanical strength that can withstand 40 post-implantation forces exerted on the tissue ${ }^{5-7}$. The mechanical properties of the scaffold are of particular importance as mechanical stimuli has been shown to regulate the differentiation response of seeded stem cells ${ }^{8}$. Ideally, the scaffolding material should mimic the property of the tissue it is replacing, and in the 45 case of adipose tissue, a Young moduli range of 3-4 $\mathrm{kPa}$ has been reported $^{9,10}$.

Cell-based tissue engineering using scaffolds offers great promise for repair of adipose tissue. Human adipose-derived stem cells (ASCs) are multipotent mesenchymal stem cells derived 50 from the stromal vascular fraction of adipose tissue, and are available abundantly as they can be isolated from adipose tissue by liposuction or abdominoplasty ${ }^{1,11,12}$. ASCs are capable of differentiating into a variety of mesenchymal lineages including mature adipocytes ${ }^{9,13,14}$. ASCs have also been shown to secrete 55 factors that trigger host stem cell migration to the implantation site, thus contributing to tissue regeneration. Increasing evidence suggested that increases in adipose tissue are associated with increases in microcirculation ${ }^{2}$. ASCs have also been shown to modulate immune response and have the potential to avoid tissue 60 rejection ${ }^{9}$. ASCs are therefore an attractive cell source for adipose tissue engineering and regenerative therapeutic applications.

The use of 3-dimensional (3D) scaffold as ASCs culturing system is considered to be advantageous compared to 2-dimensional (2D) monolayer culture, since 3D systems can closely mimic the ${ }_{65}$ microenvironment that cells experience in vivo ${ }^{15}$ Girandon et al., has demonstrated that ASC cultured in 3D scaffold expressed 
higher level of specific adipogenic markers as compared to $2 \mathrm{D}$ culture $^{16}$. A literature review by Flynn \& Woodhouse ${ }^{17}$ has summarized the results from studies that investigate the use of a range of synthetic and naturally derived scaffolds for adipose 5 tissue engineering. Although a number of scaffolds have shown to facilitate adipose tissue regeneration, new biomaterials are still required to provide multifunctional platforms that incorporate biochemical and physiochemical properties that can be beneficial to adipose tissue engineering.

${ }_{10}$ Scaffold pore sizes, porosity and pore interconnectivity are critical parameters that influence cell binding, migration, intracellular signalling, vascularization, ECM production, cell phenotype, nutrient transport, gas diffusion, and metabolic waste removal, thus determining scaffold performance. The pore size of 15 the 3D scaffold must be large enough to accommodate increase in cell number and increase in volume associated with lipid formation ${ }^{5}$ and for cells to migrate through the pores, but the pore size should also be small enough to retain a critical total surface area for appropriate cell binding ${ }^{18,}{ }^{19}$. There has not been

20 extensive research on the optimum pore size for human adiposederived stem cells. However, in general, the accepted optimum pore size of tissue scaffold for the majority of mammalian cells such as liver tissue regeneration, fibroblast ingrowth and bladder smooth muscle cell attachment and ingrowth should be within the 25 range of 38 to $500 \mu \mathrm{m}$, and the optimum porosity should be above $90 \%{ }^{18-23}$. A variety of techniques have been developed to fabricate porous structure including solvent casting, gas forming, solvent-casting and porogen leaching, solvent induced phase separation, electrospinning, emulsion freeze drying, fiber 30 bonding, or a mixture of these techniques. Although these techniques can produce highly porous scaffold, these methods have limited control over scaffold architecture, pore interconnectivity, poor strength and in some instances require the use of toxic solvent ${ }^{20-22}$. For example, solvent-casting and 35 porogen leaching method produces porous structure with controllable pore size and porosity, however the resulting scaffolds often exhibit porous structure with closed pore walls, thus impeding nutrient transport and cell infiltration within the scaffold $^{24}$.

40 There is a growing awareness of developing biomaterials using renewable resources such as cellulosic materials ${ }^{25,}{ }^{26}$. Hydroxypropylcellulose (HPC) is a commercial derivative of cellulose and Food and Drug Administration (FDA)-approved agent for drug delivery applications. HPC is available abundantly 45 at low cost, soluble in water as well as in a variety of organic solvents, commercially available in a range of molecular weights, making it an attractive biomaterial. More importantly, HPC exhibits phase transition from isotropic aqueous solution to metastable biphasic system above its lower critical solution 50 temperature ${ }^{26,27}$. In a previous study ${ }^{26}$, hydroxypropyl cellulose (HPC) was modified with allyl isocyanate containing urethane group and fabricated into a $3 \mathrm{D}$ interconnected porous scaffold by immobilizing biphasic HPC via gamma-ray irradiated crosslinking. This method produced biocompatible scaffolds with 55 interconnected macroporous structure with porosity of approximately $90 \%$. Despite the advantages of allyl isocyanate modified HPC, it is not biodegradable due to the lack of cellulose hydrolyses in vivo. In addition, polymers with repeating unit that contains urethane moiety are generally regarded to have limited 60 biodegradability. For example, polyurethanes are typically used as non-biodegradable coatings. Synthesis of biodegradable polyurethane requires the polyurethane to be produced from diisocyanate precursor such as lysine-dissocyanaate that release nontoxic degradation products such as lysine $\mathrm{s}^{28}$.

${ }_{65}$ Herein, we prepare biodegradable and macroporous scaffold structures taking advantages of the temperature responsive property of HPC. HPC was first modified with a bifunctional methacrylic anhydride (MA). The resulting conjugate contains photo-crosslinkable and hydrolytically degradable methacrylate 70 pendant group. The modified HPC conjugates, namely HPC-MA, were polymerized at its colloidal state induced by temperature mediated phase separation, thereby immobilizing the biphasic feature of HPC. The phase separation was induced in aqueous solvent simply by warming an aqueous solution containing HPC$75 \mathrm{MA}$ to above $40^{\circ} \mathrm{C}$, and avoids the use of organic solvent and thus the problem associated with harmful organic solvent residue. The physiochemical properties such as swelling ratio, porosity, mechanical properties and interior morphologies of these HPCMA scaffolds were evaluated. Cytotoxicity studies using human 80 adipose-derived stem cells (ASCs) were carried out to examine the biocompatibility of the scaffold. The current novel HPC-MA scaffold was then investigated as a support for the proliferation and adipogenesis of ASCs.

\section{Experimental}

\section{${ }_{85}$ Synthesis scheme and ${ }^{\mathbf{1}} \mathrm{H}$ nuclear magnetic resonance (NMR)}

Hydroxypropyl cellulose (HPC, $\mathrm{M}_{\mathrm{n}}$ 10, $000 \mathrm{~g} / \mathrm{mol}$, SigmaAldrich) was dehydrated by azeotropic distillation at $50{ }^{\circ} \mathrm{C}$ in toluene to remove the moisture before use. The HPC hydrogel precursor, namely HPC-MA conjugate, was prepared by 90 modifying cellulose with methacrylic anhydride (MA). Briefly, $4.0 \mathrm{~g}$ of dehydrated HPC was dissolved in $150 \mathrm{~mL}$ of chloroform followed by 4.17 mmole of methacrylic anhydride (MA). 4.17 mmole of N'N-dicyclohexylcardodiimide (DCC) was first dissolved in $3 \mathrm{~mL}$ of chloroform before adding dropwise in the ${ }_{95} \mathrm{HPC}$ chloroform mixture. The solution was stirred for $48 \mathrm{~h}$ in the presence of $0.4 \mathrm{~g}$ of 4-dimethylaminopyrinde (DMAP) as catalyst. The product was concentrated and precipitated into diethyl ether. Further purification was carried out by repeating dissolution in chloroform and precipitation into diethyl ether. 100 Finally, the product was dissolved in water, filtered, and dialyzed against deionised water for $72 \mathrm{~h}$ before lyophilisation in a freeze dryer (HETO PowerDry PL6000, Thermo Scientific). The ${ }^{1} \mathrm{H}$ NMR spectra of lyophilised HPC-MA sample were obtained in deuterated chloroform $\left(\mathrm{CDCl}_{3}\right)$ using a NMR operating at $105300 \mathrm{MHz}$ (Bruker, ACF 300).

\section{Preparation of HPC scaffolds and turbidity}

The turbidity of HPC-MA conjugate was measured to determine its lower critical solution temperature. A $10 \% \mathrm{w} / \mathrm{v}$ HPC-MA 110 aqueous solution was selected as an indication of the LCST. In brief, the lyophilised HPC-MA was dissolved in deionised water. The transmittance of the sample was monitored as a function of temperature at a fixed wavelength of $500 \mathrm{~nm}$, using a UV/Vis 
spectrophotometer (Agilent Technologies Cary 60 UV-VIS, Australia) with the sample cell thermostated by a temperature controller with circulating water bath. The transmittance was measured four times and the average transmittance values of the 5 measurement were reported

Lyophilisation HPC-MA conjugate was dissolved in deionised water $(10 \%, 15 \%$ and $20 \% \mathrm{w} / \mathrm{v}$ respectively), followed by adding 3-5 \% final concentration of 2-hydroxy-1-[4-(2hydroxyethoxy)phenyl]-2-methyl-1-propanone, known as 10 Irgacure 2959, (Sigma-Aldrich) as photoinitiator. The solution was placed in a water bath at $45{ }^{\circ} \mathrm{C}$ for 10 minutes to induce phase separation. The emulsion solution was then crosslinked in a ultra-violet ray (UV) crosslinker (Honle UV Technology, UV-F 400) for approximately 6 minutes. The crosslinked gels were then 15 washed with deionised water to remove any un-crosslinked HPCMA conjugate and photoinitiator before lyophilisation. HPC scaffold, after reaching their maximum swollen state in water in room temperature, were frozen at $-20{ }^{\circ} \mathrm{C}$ freezer and lyophilised under vacuum for $48 \mathrm{~h}$ until all water was sublimed. The 20 scaffolds prepared from $10 \%, 15 \%$, and $20 \%(\mathrm{w} / \mathrm{v})$ of HPC-MA were denoted as HPC-MA- $10 \%$, HPC-MA- $15 \%$, and HPC-MA$20 \%$, respectively.

\section{Swelling ratio and Mechanical properties}

${ }_{25}$ Swelling ratio of the scaffold was measured using a conventional gravimetrically method. The lyophilised HPC scaffolds with different polymer concentrations were submerged in water at room temperature for $48 \mathrm{~h}$. The weight of the swollen sample was obtained after wiping off excess water on the surface with a moist 30 filter paper and the dry weight of the sample was measured after drying the sample under vacuum at $25^{\circ} \mathrm{C}$ for $48 \mathrm{~h}$. The swelling ratio, $\mathrm{SR}$, of scaffold was calculated according to the equation 1 below,

$$
S R=\frac{\mathrm{w}_{\mathrm{h}}-\mathrm{w}_{\mathrm{d}}}{\mathrm{w}_{\mathrm{d}}}
$$

35 where $W_{h}$ is the weight of the scaffold in the swollen equilibrium and $W_{d}$ is the weight of the dried scaffold. Each sample was measured three times from the four replicate specimens and the average value of the measurement was taken.

Compression test was carried out to determine the mechanical 40 properties of hydrated scaffolds with different polymer concentrations using a dynamic mechanical analyzer (TA Instruments, Q800) at a frequency of $1 \mathrm{~Hz}$ and a preload of 0.01 $\mathrm{N}$. The testing was performed under atmospheric condition and $298 \mathrm{~K}$. The compression testing was performed in quadruplicate.

45

Interior morphology, porosity and mercury intrusion
porosimetry

The lyophilised sample of different polymer concentrations were fractured carefully and their interior morphology was studied by 50 using a scanning electron microscope (SEM) (FEI Quanta 200 ESEM with EDAX Si(Li) X-ray detector and Gatan Alto Cyro stage) after the sample have been coated with gold and palladium for $30 \mathrm{~s}$.

The interconnecting pores in the HPC-MA scaffold were
${ }_{55}$ assessed by performing Focused Ion Beam (FIB) milling to probe the scaffold interiors, similar to the approach detailed in AlAbboodi et $\mathrm{al}^{29}$. All FIB/SEM experiments were based on Helios Nanolab 600 (FEI company), and a highly focused ion beam (30 $\left.\mathrm{kV}, \mathrm{Ga}^{+}\right)$of large current $(21 \mathrm{nA})$ was used to ablate an area of 60 approximately $500 \times 500 \mu \mathrm{m}$ on the scaffolds. The ablation process was continuously monitored by SEM, until an ablation depth close to $50 \mu \mathrm{m}$ has been achieved.

The porosities of the scaffolds were determined using the solvent replacement method. In brief, lyophilised samples were ${ }_{65}$ first submerged in absolute ethanol for $24 \mathrm{~h}$, and weighted after excess ethanol on the surface was blotted. Each sample was measured three times from the four replicate specimens and the average value of the measurement was taken. The porosity of the scaffold was calculated according to the equation 2 below,

70

$$
\text { Porosity }=\frac{\mathrm{M}_{\mathrm{h}}-\mathrm{M}_{\mathrm{d}}}{\rho V_{t}} \times 100 \%
$$

where $M_{d}$ and $M_{h}$ are the weight of scaffold before and after the immersion in absolute ethanol respectively. $\rho$ is the density of absolute ethanol and $V_{t}$ is the total volume of the scaffold.

75 The pore size distribution was determined using a mercury intrusion porosimetry (MIP) method. The interconnected pore size distribution of the lyophilised scaffold was measured out by carefully fractured into the desired size and weight before testing using a mercury porosimeter (Autopore III, Micromeritics Co.).

80

\section{Degradation study}

Degradation study was carried out using the HPC-MA hydrogel disks at different concentrations with dimensions of $1 \mathrm{~cm}$ diameter and $1 \mathrm{~mm}$ thickness. It is known that polymer 85 containing ester linkage undergoes hydrolysis in the present of phosphate buffered saline solution $(\mathrm{PBS})^{30,31}$, therefore, the degradation study of HPC-MA hydrogel contains hydrolytically degradable methacrylate pendant group (ester linkage) was carried out in PBS solution. The hydrogel disks were incubated in $905 \mathrm{~mL}$ of PBS (pH 7.4) at $37{ }^{\circ} \mathrm{C}$ and shaken at $150 \mathrm{rpm}$ for 40 days in a shaking incubator. The PBS solution was replaced every 5 days throughout the study. At pre-determined time points (5 days), the samples were rinsed with deionised water, dried in a vacuum oven for $48 \mathrm{~h}$ at $40{ }^{\circ} \mathrm{C}$. Their weight loss was then 95 recorded. These experiments were performed with four replicates.

\section{Surface functionalization of scaffold and cell culture of adipose-derived stem cells (ASCs)}

Lyophilised HPC-MA-10 wt\% scaffolds were decontaminated by 100 soaking in $70 \%$ ethanol overnight followed by washing with sterile phosphate buffered saline (PBS) before surface functionalisation. Sterilized scaffolds were activated in $40 \mathrm{nM}$ 1,1 '-carbonyldiimidazole (CDI) in acetone at room temperature for $3 \mathrm{~h}$. The activated scaffolds were then washed in acetone for 3 105 to 4 times to remove any unreacted traces of CDI. After washing, the activated scaffolds were treated with gelatin $\left(1.16 \mathrm{mg} \mathrm{mL}^{-1}\right)$ in a sodium bicarbonate $\left(\mathrm{NaHCO}_{3}\right)$ buffer $(50 \mathrm{mM}, \mathrm{pH}$ 9) at room temperature for $24 \mathrm{~h}$. The conjugated scaffolds were washed 
twice with sterile PBS before lyophilisation.

StemPro ${ }^{\circledR}$ human derived stem cells (P3) were cultured in a complete media comprising of Dulbecco's Modified Eagle Medium Nutrient Mixture F-12 (DMEM-F12), supplemented 5 with $10 \%$ Fetal Bovine Serum, $1 \%$ non Essential Amino Acid, 1 $\%$ L-glutamine and $1 \% \mathrm{P} / \mathrm{S}$ solution at $37{ }^{\circ} \mathrm{C}$ in a humidified atmosphere of $5 \% \mathrm{CO}_{2}$ (all chemicals and cells were obtained from Life Technologies). The media was changed every $48 \mathrm{~h}$.

ASCs were trypsinised using $0.25 \%$ trypsin upon confluence 10 and seeded onto the sterilized scaffolds. The scaffolds were decontaminated by immersion in ethanol for $24 \mathrm{~h}$ with subsequent change of ethanol every $4 \mathrm{~h}$, followed by rinsing in phosphate buffered saline (Life Technologies) and final immersion in DMEM-F12 solution. The scaffolds were 15 subsequently dried and $30 \mu \mathrm{l}$ of cell suspension was added dropwise at a density of 34,000 cells $/ \mathrm{cm}^{3}$ to the scaffold. After 4 hours, complete media was added for subsequent culture. Adipogenesis of ASCs in the scaffolds was also carried out by supplementing the cells with adipogenic media. The media was 20 changed every 3 days.

\section{Morphology and proliferation of ASCs in scaffolds}

The surface and cross-sectional morphologies of the scaffolds as well as ASCs morphology after 14 days of in vitro culture were 25 analysed using the scanning electron microscopy (SEM) (JEOL JSM-5410, Japan). The cell-scaffolds were first fixed in $2.5 \%$ gluteraldehyde for $2 \mathrm{~h}$, followed by a series of dehydration in graded ethanol $(50 \%, 70 \%, 80 \%, 90 \%)$ with 15 min incubation at each interval, and final immersion in $100 \%$ ethanol for $30 \mathrm{~min}$.

30 Hexamethyldisilazane was subsequently added to the scaffolds and left to incubate for $1 \mathrm{~h}$ before removal and left for overnight drying at room temperature. The scaffolds were subsequently frozen in liquid nitrogen before being freeze-fractured into several sections and coated with gold prior to imaging. An 35 acceleration voltage of $5 \mathrm{kV}$ was used and images were obtained at different magnifications.

The capability of ASCs to proliferate in the scaffolds was analyzed using the alamarBlue ${ }^{\mathbb{B}}$ assay on days 2,4 and 7. At each time point, $200 \mu \mathrm{l}$ of $10 \%$ alamarBlue ${ }^{\circledR}$ dye (diluted with 40 complete medium) was added to each scaffold and incubated for $4 \mathrm{~h}$ at $37^{\circ} \mathrm{C}$ in a humidified atmosphere of $5 \% \mathrm{CO}_{2}$. Fluorescence analysis using an excitation wavelength of $570 \mathrm{~nm}$ and emission wavelength of $585 \mathrm{~nm}$ was carried out with Thermoscientific Varioskan Flash Multimode Reader. The number of cells 45 corresponding to the particular relative fluorescence unit (RFU) was subsequently obtained from the standard curve (plot of RFU vs. known cell numbers).

\section{Adipogenic characterization of ASCs and gene expression} ${ }_{50}$ (RT-PCR)

Day 2, 4, 7 and 14 cell cultured scaffolds were fixed in $4 \%$ paraformaldehyde (Sigma-Aldrich) for $30 \mathrm{~min}$ and cryosectioned into thin sections of $30 \mu \mathrm{m}$ each. $200 \mu \mathrm{l}$ of $60 \%$ Oil Red O stain (Sigma-Aldrich) was added onto the sections and left to incubate 55 for $5 \mathrm{~min}$ before imaging under the light microscope (Carl Zeiss Primo Vert).
Adipogenesis of ASCs in the scaffolds was also determined by quantifying the amount of adiponectin and leptin released over a period of 14 days using Human Adiponectin and Leptin ELISA 60 assay kits (Raybiotech). All media was collected at each media change and frozen at $-80{ }^{\circ} \mathrm{C}$ before testing. The assays were performed according to manufacturer's instructions. Fluorescence analysis was carried out at $450 \mathrm{~nm}$ using the Gemini EM Microplate Reader.

65 Adipogenic differentiation of ASCs after 14 days of culture in the adipogenic medium was also confirmed by RT-PCR analysis. Undifferentiated ASCs cultured in complete DMEM-F12 media was also used as a control. Scaffolds were homogenized in trizol reagent and the RNA was extracted using the Total RNA kit I 70 (Omega Bio-Tek). The cDNA was synthesized from the total RNA using iScript ${ }^{\mathrm{TM}}$ cDNA Synthesis Kit (Biorad). The cDNA was used as the template in a $20 \mu \mathrm{l}$ reaction mixture containing specific primer pair of each cDNA according to the sequences with SYBR $^{\circledR}$ Green Supermix (Biorad) (Table 1) for PCR 75 analysis. The mRNA levels were normalized to those of GAPDH, and changes in gene expression were calculated as fold changes (the $\Delta \Delta \mathrm{Ct}$ method).

Table 1 PCR primers

\begin{tabular}{ccc}
\hline Gene & $\mathbf{5}$ ' to 3' Sequence (sense) & 5' to 3' Sequence (antisense) \\
\hline GAPDH & CCCCTTCATTGACCTCAACTACA & TTGCTGATGATCTTGAGGCTGT \\
PPARG & CTCCTATTGACCCAGAAAGC & GTAGAGC TGAGTCTTCTCAG \\
LPL & ATGGAGAGCAAAGCCCTGCTC & GTTAGGTCCAGCTGGATCGAG \\
85 & & \\
Leptin & GTGCC-TATCCAGAAAGTCCAG & TCAGCATTCAGGGCTAACA TC \\
Adiponectin CATGACCAGGAAACCACGACT & TGAATGCTGAGCGGTAT \\
\hline
\end{tabular}

\section{${ }_{90}$ Statistical Analysis}

All experiments were performed in at least three replicates. Results were reported as average value \pm standard deviation. One-way analysis of variance (ANOVA) was used to compare multiple groups of data statically; $p$ values lower than 0.05 were 95 considered statistically significant.

\section{Results and discussion}

\section{HPC-MA characterization and hydrogel preparation}

HPC-MA conjugate was synthesized by modifying HPC by MA 100 as depicted in Fig. 1a. The degree of substitution (DS) was $\sim 0.35$ as calculated by ${ }^{1} \mathrm{H} \mathrm{NMR}$ in $\mathrm{CDCl}_{3} .{ }^{1} \mathrm{H} \mathrm{NMR}\left(\mathrm{CDCl}_{3}, \delta \mathrm{ppm}\right)$ : 0.5-1.5 (- $\left.\mathrm{CH}_{3}-\mathrm{CH}-\right), 1.8-2.0 \quad\left(\mathrm{CH}_{3}-\mathrm{C}=\mathrm{CH}_{2}\right)$, 5.5-6.2 $\quad\left(-\mathrm{C}=\mathrm{CH}_{2}\right)$, 2.5-5.3 (other protons) (Fig. 1b). The degree of modification is defined as the substitution degree of available - $\mathrm{OH}$ groups on the 105 HPC chain. Fig. 1c demonstrated that the HPC-MA retains the phase behaviour characteristic of HPC. The LCST of HPC-MA was determined to be approximately 40 to $41{ }^{\circ} \mathrm{C}$, after which the transmittance decreases drastically with increasing temperature until reaching a plateau at $\sim 45^{\circ} \mathrm{C}$. HPC-MA with 0.35 DS was 110 selected as an example for scaffold preparation. Porous HPC-MA hydrogel was produced using simple procedures without the use of porogens as illustrated in Fig. 1d. HPC-MA conjugates with 
0.35 DS are water-soluble and formed single-phase solution when dissolved in aqueous solution (Fig. 1d Step 1). HPC-MA exhibited low critical solution temperature (LCST) transition at around $40^{\circ} \mathrm{C}$. Upon heating the solution above its LCST, HPA5 MA solution underwent phase transition from isotropic solution to colloidal solution (Fig. 1d Step 2). Fixation of the colloidal structure of HPC-MA was achieved by polymerizing the HPCMA conjugate and produced an opaque hydrogel (Fig. 1d Step 3). UV-irradiation was selected to induce photopolymerisation due to 10 its many advantages including fast polymerization rate at low temperature, and ease of hydrogel shaping ${ }^{32}$, Irgacure 2959 has been demonstrated to cause minimal toxicity to a wide range of mammalian cells ${ }^{33}$, and was employed as a photoinitiator in this study. Further lyophilisation of the hydrogel produced highly 15 porous structures (Fig. 1d Step 4). HPC-MA-10 \%, HPC-MA-15 $\%$ and HPC-MA-20 \% hydrogel samples were prepared and subjected to characterization, and will be described in later sections.
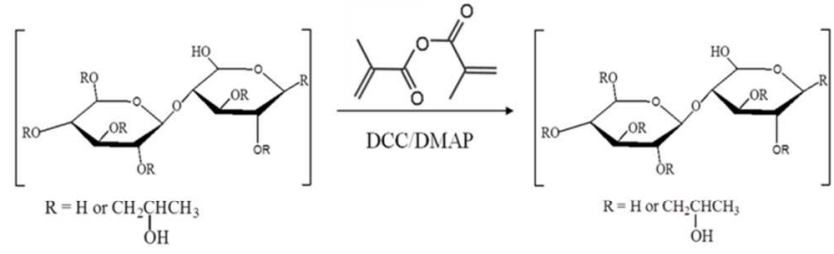

$\mathrm{OH}$

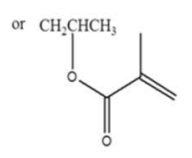

20

Fig. 1a Synthesis scheme of HPC-MA

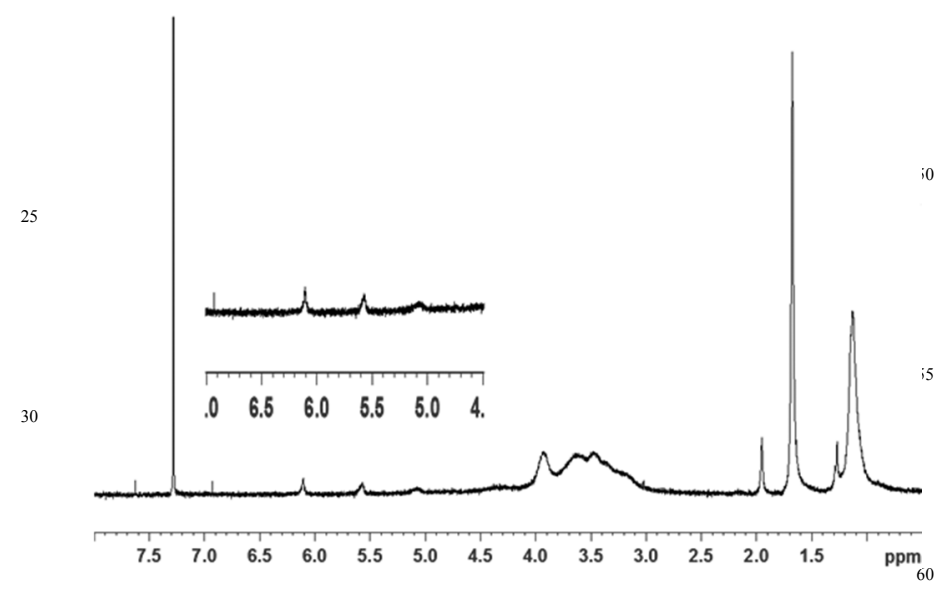

Fig. 1b NMR of $\mathrm{HPC}-\mathrm{MA}$ in $\mathrm{CDCl}_{3}$

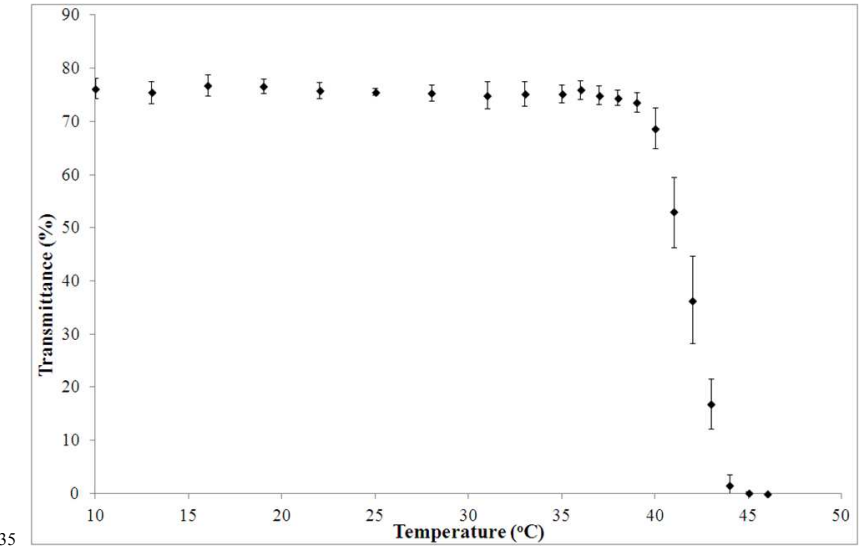

Fig. 1c Turbidimetry measurement for HPC-MA-10 wt $\%$. The data are shown as mean values with standard deviation as error bars in the form of mean value \pm standard deviation.

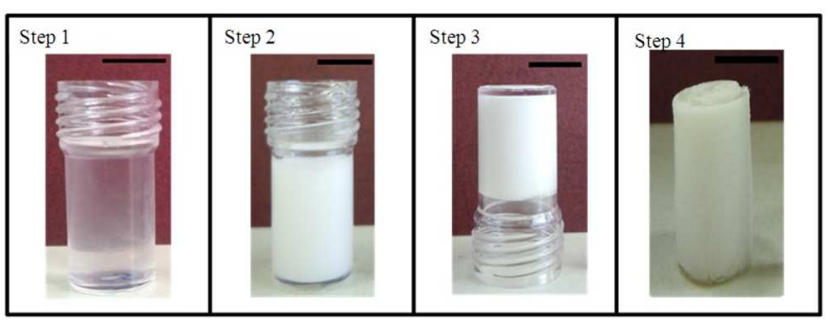

40 Fig. 1d Preparation of HPC-MA scaffold (scale bar $1.0 \mathrm{~cm}$ ) from (Step 1) homogenous solution of HPC-MA-10 wt $\%$ at room temperature, to (Step

2) phase separated colloidal fluid at $\sim 45^{\circ} \mathrm{C}$, (Step 3) crosslinked heterogeneous gel at room temperature and (Step 4) freeze-dried scaffold.

\section{Swelling ratio and mechanical properties}

${ }_{45}$ Fig. 2 summarizes the swelling ratios (SR) of the lyophilised HPC scaffolds in water and the storage modulus of hydrated HPC-MA at room temperature. Swelling ratio is a measure of wettability of a material. Hydrogels with high swelling ratio are highly permeable, which facilitates oxygen, nutrient and ;0 metabolites exchange, and are considered as promising material for tissue scaffolding ${ }^{34}$. It was seen that the three different HPCMA concentration exhibits high SR attributed to the presence of hydroxyl groups on the HPC chain that attract water molecules from the surrounding environment. The SR was found to be is decreasing with increasing HPC-MA concentration $(\mathrm{p}<0.05, \mathrm{n}=$ 4), whereas HPC-MA-10\% had the highest SR of 35.83 while the SR of HPC-MA-15\% and HPC-MA-20\% were found to be 19.16 and 12.94 , respectively. It is well known that crosslinking density has a strong influence on the swelling ratio of hydrogel ${ }^{35-39}$. The

60 number of crosslinking bonds per volume, known as crosslinking density, increases with increasing polymer concentration. As the crosslinking density increases, the water molecules and watersoluble substances will find it hard to infiltrate into a densely crosslinked network, thus, resulting in lower swelling ratio.

65 Biological tissues and organs are soft viscoelastic materials, which display a wide range of mechanical properties tailored for their specific physiological function. Change in tissue stiffness is generally associated with pathological disease or tissue dysfunction $^{10,40}$. Accumulative evidences suggest that substrate

70 mechanics and the topography of extracellular microenvironment can regulate cell phenotype similar to the influence of biochemical signals ${ }^{41,42}$. Mechanical strength is therefore an 
important property of hydrogel scaffold. For tissue regeneration to be successful, it is believed that the mechanical properties of scaffold should match roughly the mechanical properties of tissue growth in order to provide cells with instructive 5 microenvironment. The storage modulus of HPC-MA-10\%, 15\% and $20 \%$ were found to be $0.75,1.87$ and $4.28 \mathrm{KPa}$, respectively. As expected, the storage modulus increased with increasing HPCMA concentration $(\mathrm{p}<0.05, \mathrm{n}=4)$. It is well known that hydrogel with higher precursor mass exhibit stronger mechanical 10 properties, as the crosslinking degree increases due to formation of longer attached chain ${ }^{36,43}$. The storage modulus of the HPCMA hydrogels are comparable to that of soft tissues and organs such as brain, lymph node, mammary gland, liver, breast tumor and kidney ${ }^{10}$, and suggesting that the HPC-MA hydrogels can be 15 used as tissues scaffolds to mimic these soft tissues. These results prove that the swelling ratio and mechanical properties of the hydrogel can be tuned by altering the crosslinking density ${ }^{36}$.

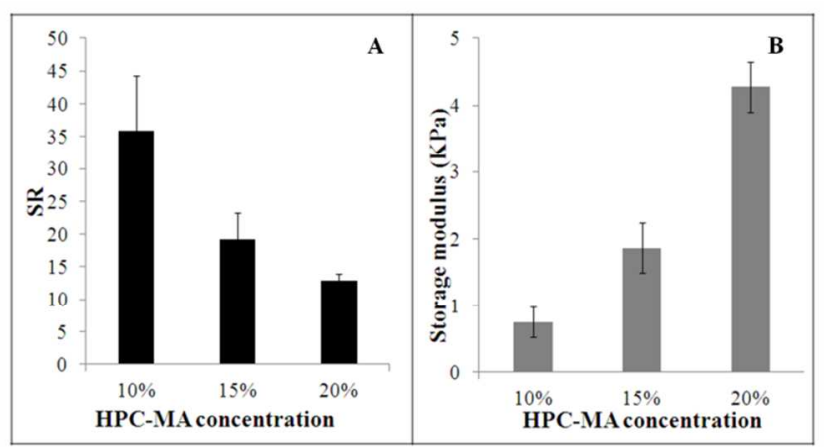

Fig. 2 Swelling ratio (A) and storage modulus (KPa) (B) of HPC-MA-10 $20 \mathrm{wt} \%, 15 \mathrm{wt} \%$ and $20 \mathrm{wt} \%$ hydrogels at room temperature respectively. The data are shown as mean values with standard deviation as error bars in the form of mean value \pm standard deviation.

\section{Physiochemical properties of hydrogels}

${ }_{25}$ HPC-MA scaffold with interconnected porous structure was fabricated by polymerizing colloidal HPC-MA solution followed by lyophilisation. It is well known that polymerization in colloidal solution generates open-cell structure i.e. interconnected porous structure with water channels throughout the network ${ }^{43,44}$.

30 Fig. 3A-F shows the cross sections of the three different concentrations of lyophilised HPC-MA scaffolds visualized and characterized using SEM at low and high magnification. As expected, the SEM images revealed that all the HPC-MA scaffolds were highly porous with interconnected pores. The 35 degree of interconnection was assessed by mercury porosimetry and Focused ion bean milling - scanning electron microscopy (FIB-SEM). The mercury porosimeter method is a common technique used by many groups to quantify interconnected porosity, as mercury porosimetry only measures the 40 interconnected channels in a microstructure, the result has therefore been used to verify the interconnectivity of a microstructure ${ }^{45-49}$. FIB milling has been used as a new technique to assess the $3 \mathrm{D}$ porosity of hydrogel ${ }^{29}$, the FIB/SEM also allows a precise visualization of the interconnectivity of scaffold.

${ }_{45}$ Representative images in Fig. 4a (A) and (B) showed the crosssection of HPC-MA- $10 \%$ before FIB milling and after a $50 \mu \mathrm{m}$ layer has been removed, respectively. Interconnections between different pores in these two layers were observed, which further verified the interconnectivity of the scaffolds. Such ${ }_{50}$ interconnected pores are needed for cell infiltration, unrestricted cell-cell signalling, and nutrient transport to take place. Mercury porosimeter measurements further confirmed the presence of highly interconnected macroporous structure in HPC-MA-10\%, $15 \mathrm{wt} \%$ and $20 \mathrm{wt} \%$. Representative pore size distribution graphs 55 are shown in Fig. 4b. All scaffolds had pore size ranging from 30 to $330 \mu \mathrm{m}$. HPC-MA-10\%, HPC-MA-15\% HPC-MA-20\% exhibited median mean pore diameter of $69.4,45.1$, and $42.4 \mu \mathrm{m}$, respectively. The pore size of HPC-MA scaffold depends on the polymer concentration as expected. It was found that a decrease 60 in the average value of median pore size $(p<0.05, n=4)$ was associated with increase in polymer concentration as expected. It is well known that high crosslinking density will result in smaller pore size due to the highly intramolecularly crosslinked copolymers $^{50}$. Nonetheless, all three scaffolds were highly ${ }_{65}$ porous. The interconnected porosities determined by mercury intrusion porosimetry for HPC-MA-10\%, HPC-MA-15\%, and HPC-MA-20\% were found to be $93 \pm 0.8 \%, 94 \pm 0.7$, and $96 \pm 0.9$ $\%$, respectively. There is no significant difference between the porosity measurements obtained using solvent replacement 70 method and the porosity measurements obtained using mercury intrusion porosimetry $(\mathrm{p}>0.05, \mathrm{n}=4)$. These results suggest that induced phase separation technique is able to create highly interconnected macroporous and high porosity $3 \mathrm{D}$ structure.
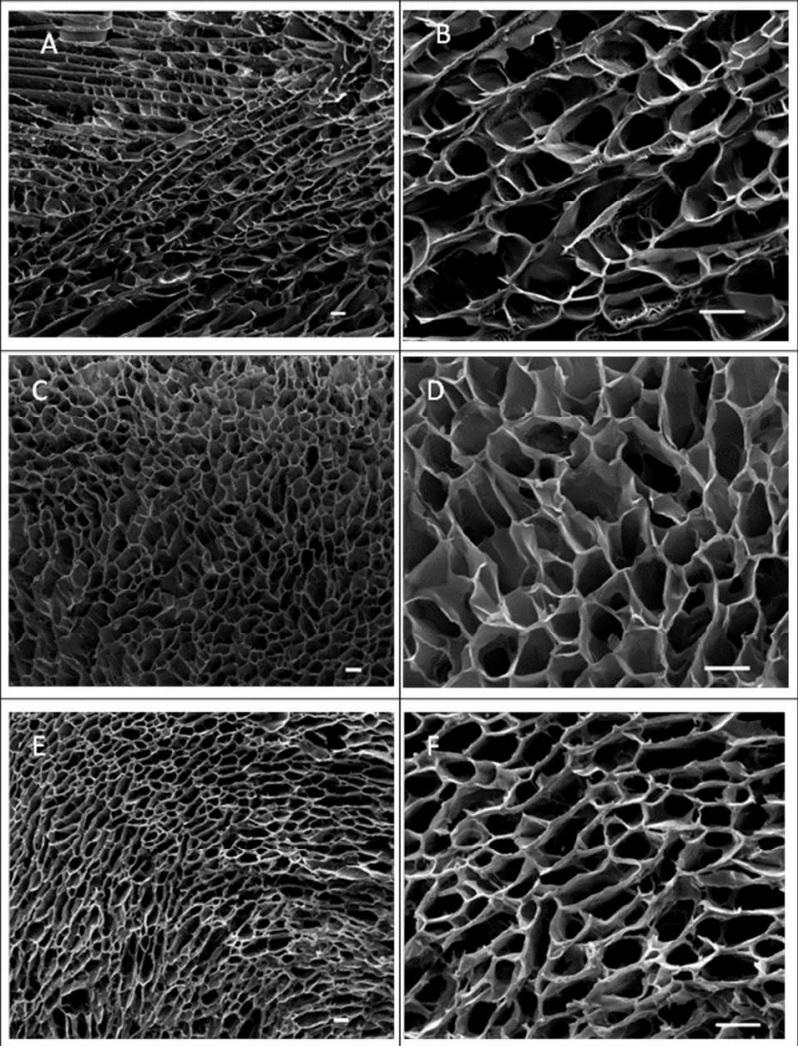

75 Fig. 3 Pore size and morphology of HPC-MA scaffolds. (A) and (B), (C) and $(\mathrm{D}),(\mathrm{E})$ and $(\mathrm{F})$ are representative cross-sectional SEM micrographs of lyophilised HPC-MA-10 wt $\%, 15 \mathrm{wt} \%$ and $20 \mathrm{wt} \%$, at low and high magnification (scale bar $100 \mu \mathrm{m}$ ), respectively. 


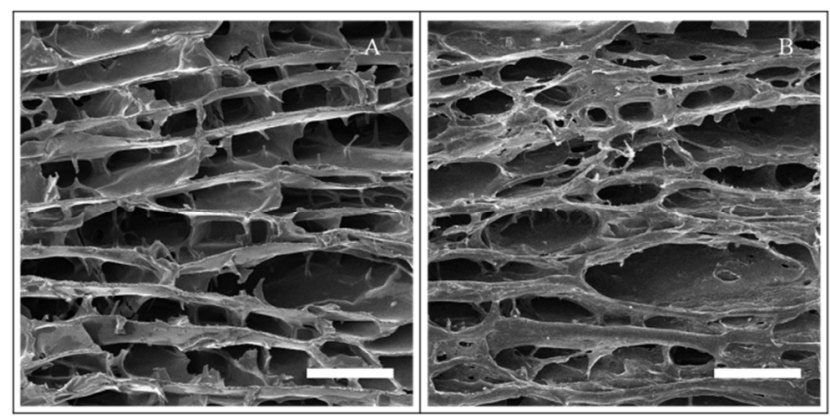

Fig. 4a FIB/SEM of HPC-MA-10 wt\% (scale bar $100 \mu \mathrm{m}$ ), top view SEM image of the scaffold before milling (A), after a layer of approximately $50 \mu \mathrm{m}$ in thickness milled off by FIB (B).

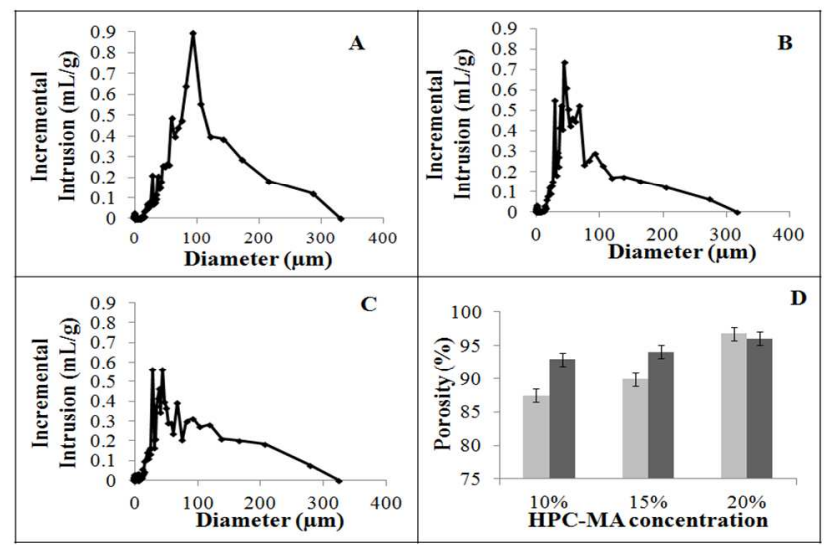

Fig. 4b Pore size distribution of HPC-MA-10 wt \% (A), $15 \mathrm{wt} \%$ (B) and $20 \mathrm{wt} \%$ (C); Porosity ( $\square$ ) and interconnected porosity ( $)$ of HPC-MA scaffold (D). The data are shown as mean values with standard deviation as error bars in the form of mean value \pm standard deviation.

10

\section{Degradation profile}

For successful tissue regeneration, a tissue scaffold should provide sufficient mechanical support for cell proliferation before new tissue growth, but it should degrade and resorb at a rate that 15 matches the new tissues growth rate ${ }^{51}$. Cellulose possesses many favourable properties that make it attractive as a tissue scaffold materials ${ }^{26}$. However, cellulose is generally regarded to have limited in vivo degradability due to the absence of appropriate hydrolases. The subcutaneous implantation of cellulose sponge 20 was studied ${ }^{52}$ and a decrease in implant size was observed after 16 weeks, however it is suggested that the complete disappearance of cellulose sponge will take longer than 60 week. The degradation of an allyl isocynate modified HPC hydrogel was studied ${ }^{26}$ over a period of 12 weeks and observed no 25 significant degradation. To improve the degradability of HPC hydrogel, a bifunctional linker MA was incorporated into HPC as pendant group. It is well known that MA can be radically polymerized to form polyester network and the resulting ester linkages are hydrolytically degradable ${ }^{53,54}$. The hydrolytic 30 degradation of HPC-MA hydrogels was monitored by measuring the weight loss of samples over time, and the results were presented in terms of weight percentage remaining against time. Fig. 5 shows the degradation profile of HPC-MA hydrogels with different polymer concentration over a period of 40 days in PBS. 35 All HPC-MA hydrogels underwent degradation after 5 days of incubation in PBS, indicating that the use of degradable crosslinker methacrylate anhydride has greatly improved the degradability of cellulose hydrogel. The degradation of HPCMA- $10 \%$ was the fastest with a remaining weight of 40 approximately $10 \%$ after 40 days. The percentage of remaining weight of HPC-MA-15\% was approximately $30 \%$ after 40 days, whereas the percentage of remaining weight of HPC-MA- $20 \%$ was approximately $50 \%$ after 40 days. As expected, the hydrogels prepared from higher HPC-MA concentration showed slower 45 degradation $(\mathrm{p}<0.05, \mathrm{n}=5)$. It is known that polyesters degrades by hydrolytic cleavage of the ester linkage, the degradation rate is highly dependent on the crosslinking density ${ }^{55}$ 56. The degradation is slower in tightly crosslinked network due to the lower water accessibility, hence slower hydrolysis rate. The data 50 obtained in this work illustrates that varying the polymer concentration can alter the degradation rate of HPC-MA hydrogel.

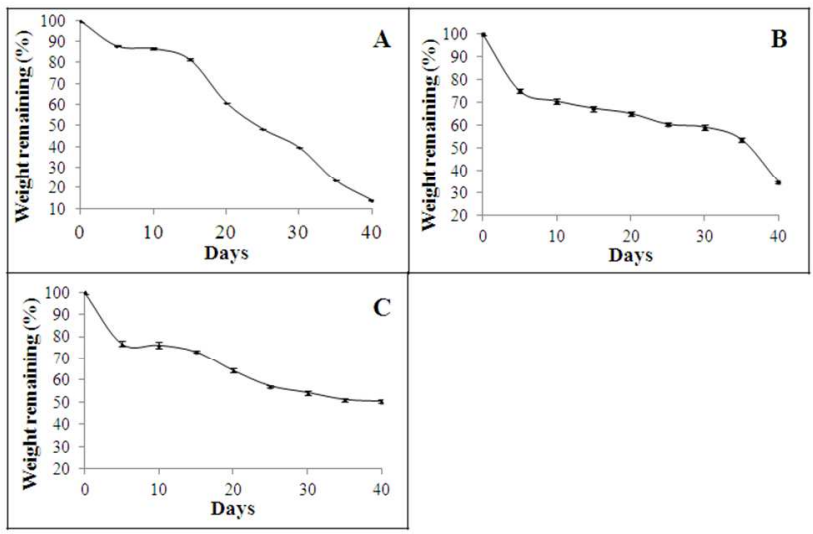

Fig. 5 Degradation profile of HPC-MA-10 wt \% (A), $15 \mathrm{wt} \%$ (B) and 20 $55 \mathrm{wt} \%(\mathrm{C})$. The data are shown as mean values with standard deviation as error bars in the form of mean value \pm standard deviation, and the standard deviations appear to be small.

\section{Surface functionalization of scaffold and cell proliferation in ${ }_{60}$ hydrogel scaffold}

Most mammalian cells are anchorage dependent, therefore, cell adhesion to the extracellular matrix (ECM) plays important role in regulating cell survival, cell cycle progression, tissue-specific phenotype expression, organogenesis, wound healing, tissue 65 homeostasis and remodelling ${ }^{57}$. An ideal tissue scaffold should provide cell adhesion sites. HPC as a commercial derivate of cellulose has many favourable properties as biomaterials ${ }^{23,58}$, but it does not contain any cell-recognizable signal molecules that can mediate mammalian cell adhesion. To achieve cell-substrate 70 interaction, the scaffold surface can be functionalized with biochemical cues after scaffold fabrication ${ }^{59}$. To demonstrate the feasibility to introduce biochemical cues to the HPC-MA hydrogel to enable cell adhesion, the surface of HPC-MA-10\% was activated by CDI followed by conjugation with gelatin. ${ }_{75}$ Gelatin contains arginine-glycine-aspartate (RGD) peptide sequence that can mediate cell-substrate interaction ${ }^{34,}$ 60. To evaluate the feasibility of using HPC-MA hydrogels as 3D scaffold for adipose tissue engineering, ASCs were cultured for 21 days in the scaffold with adipogenic medium and analyzed 
using SEM. Fig. 6A and 6B show the presence of ASCs on the surface and cross section of scaffolds, respectively.. These results indicated that the HPC-MA scaffold supported the growth of ASCs, as well as infiltration into the scaffold (Fig. 6B), 5 demonstrating its high-interconnected porosity. In addition, using alamarBlue ${ }^{\circledR}$ as an indirect indicator of cell proliferation, the number of ASCs was observed to increase gradually over a period of 7 days from the cell proliferation data, which indicated that the material properties of the scaffold supported the growth 10 of ASCs (Fig. 7). It is noted that cells are seeded onto HPC-MA scaffolds using a typical static seeding method which may not result in optimal seeding efficiency or optimal cell distribution. In subsequent study, alternative cell seeding method such as surface acoustic wave driven seeding method ${ }^{61}$ can be employed to 15 improve the seeding efficiency.

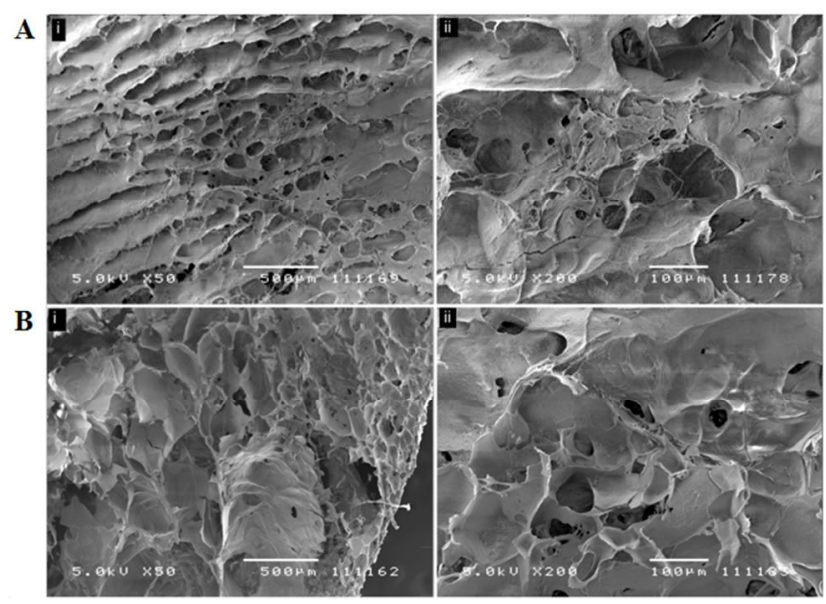

Fig. 6 SEM micrographs illustrating the presence of ASCs on the (A) 20 surface and (B) cross-section of Day 14 cell cultured HPC-MA- $10 \mathrm{wt} \%$ scaffolds at (i) $50 \mathrm{X}$ and (ii) $200 \mathrm{X}$ magnifications.

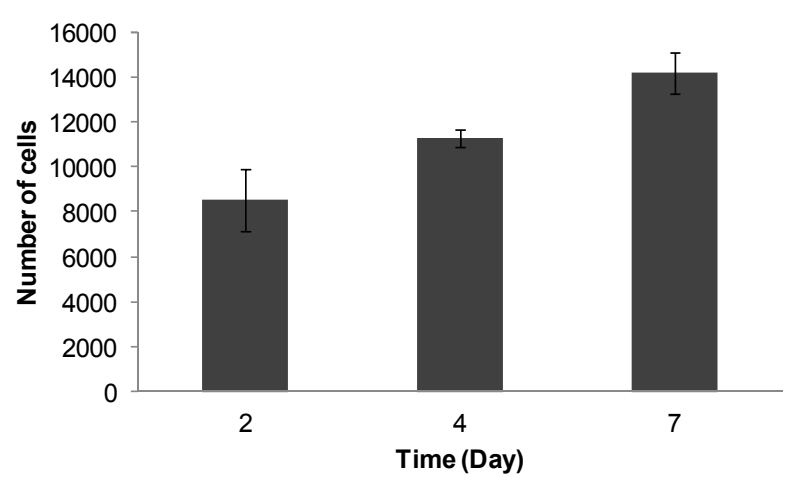

Fig. 7 Number of ASCs in the HPC-MA-10 wt $\%$ scaffolds over a period of one week.

\section{Adipogenic characterization}

The differentiation capability of ASCs that were cultured in the scaffolds with adipogenic supplements was also studied. It is very well known that adipogenesis is enhanced on scaffolds with stiffness similar to that of in vivo adipose tissue ${ }^{62,63}$. After 30 studying the mechanical characterization results above, HPCMA- $10 \%$ was selected for this study since it exhibits a storage modulus closest to that of adipose tissue ${ }^{64}$ in comparison to the other two scaffold formulations. Adipogenic differentiation of ASCs into adipocytes inside the scaffolds was evaluated by Oil ${ }_{35}$ Red O (ORO) staining ${ }^{65}$. Fig. 8A illustrates the typical ORO staining image of a fat tissue, while Fig. $8 \mathrm{~B}-\mathrm{C}$ show the oil content of Day 14 ASCs grown on a two-dimensional (2D) tissue culture plate (TCP) without and with adipogenic medium, respectively. It was observed that ASCs did not differentiate into 40 adipocytes in the absence of adipogenic medium. From Fig. 8c, an increase in the oil content in the ASCs grown in the scaffolds could be observed over a period of 14 days. From the results, an absence of stained lipid content was observed on Day 2, thereby showing the absence of adipogenesis at this initial stage. From ${ }_{45}$ Day 4 onwards, lipid droplets that were stained red were observed and the amount of lipid content increases with longer period of culture. A large amount of oil content was observed on Day 14. Adipogenic differentiation of ASCs into adipocytes in the scaffolds was further confirmed by the release of adiponectin 50 and leptin into the medium. Similar to ORO staining, both adiponectin (Fig. 9A) and leptin (Fig. 9B) release began on Day 4 , and the amount of adiponectin and leptin released increased significantly after 14 days of culture $(\mathrm{p}<0.05, \mathrm{n}=3)$. In addition, the amount of adiponectin released was much higher than leptin 55 over the same period of time. Hence, ASCs were also capable of differentiating into adipocytes in the scaffolds. Evidence is emerging that physical culture conditions play a major role in determining stem cell fate to an extent that surpasses the influence of growth and differentiation factors ${ }^{66-68}$. Of particular ${ }_{60}$ relevance to this work is the discovery that geometric factors play important role in regulating the commitment of stem cell fate. For instant, well-spread mesenchymal stem cells (MSCs) underwent osteogenesis, while un-spread cells underwent adipogenesis ${ }^{69,70}$. Ruiz \& Chen demonstrated that MSCs underwent osteogenesis at 65 convex edges and adipogenesis at concave edges ${ }^{71}$. It was observed that the HPC-MA scaffolds contain large number of concave pores as compared to convex edges, the provision of large number of concave pores in HPC-MA scaffolds may also promote adipogenesis of ASCs.

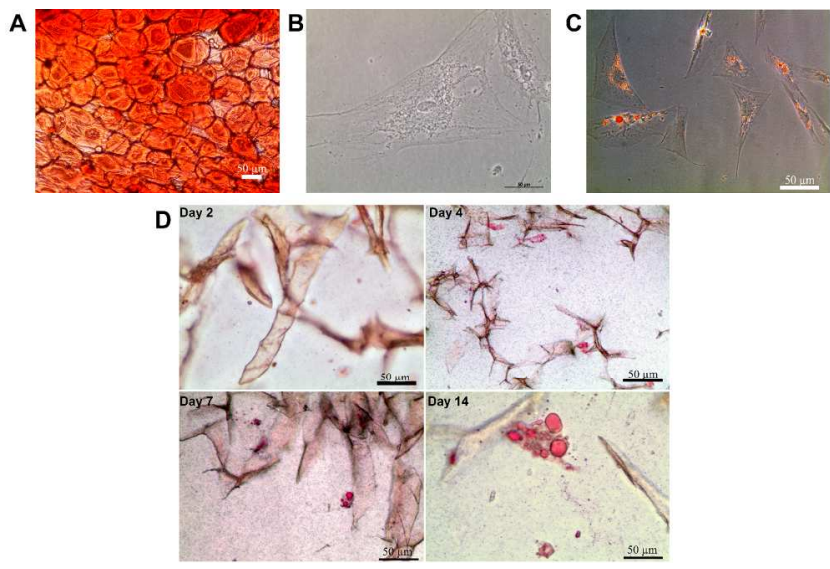

Fig. 8 Oil Red O staining of the lipid droplets of (A) fat tissue, (B) ASCs grown on 2D TCP without adipogenic supplement, (C) ASCs grown on 2D TCP with adipogenic supplment (Day 14), and (D) ASCs grown in the 3D HPC-MA- $10 \mathrm{wt} \%$ scaffold over a period of 14 days and lipid droplets 75 were observed to be present from Day 4 onwards. Scale bar $50 \mu \mathrm{m}$. 

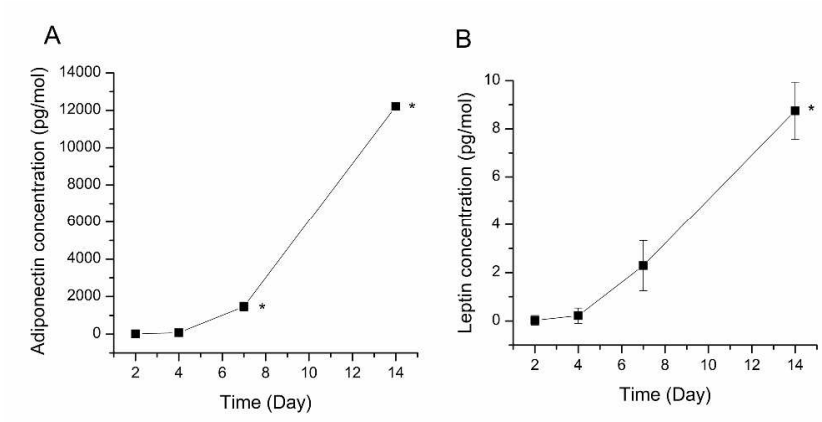

Fig. 9 Amount of (A) adiponectin and (B) leptin released into the medium over a period of 14 days. Both adiponectin and leptin were released from Day 4 onwards, and the amount released increased significantly after 14

5 days of culture $(* \mathrm{p}<0.05, \mathrm{n}=3)$. The data are shown as mean values with standard deviation as error bars in the form of mean value \pm standard deviation, and the standard deviations appear to be small.

\section{Gene expression (RT-PCR)}

10 Adipogenic differentiation of ASCs in the scaffolds was further confirmed by evaluating the gene expression levels of adipogenic markers. The fold change values for ASCs cultured with adipogenic supplements in the scaffold was compared to the undifferentiated ASCs cultured on TCP (control) for the

15 adipogenic genes (PPARG, LPL, leptin and adiponectin). ASCs subjected to differentiation in the scaffold displayed fold change values that were much higher than the control for early adipogenic markers (PPARG and LPL) $(\mathrm{p}<0.05, \mathrm{n}=3)$ (Fig. 10A) and late adipogenic markers (adiponectin and leptin) $(\mathrm{p}<0.05$, $20 \mathrm{n}=3$ ) (Fig. 10B). The upregulation of adipogenic stem cell markers suggests that the $3 \mathrm{D}$ scaffold together with the adipogenic supplements led to the differentiation of ASCs into adipocytes. The successful adipogenesis could also be attributed to the use of a 3D matrix with mechanical stiffness matching that

25 of native adipose tissue. It is worthwhile to mention that scaffold mechanical properties

play an important role in directing stem cell niche and ASCs

are capable of differentiating into a variety of cell types not limiting to adipocyote ${ }^{9,13}, 14$. In subsequent study, HPC-MA

30 scaffolds with higher storage modulus can be employed as $3 \mathrm{D}$ adipose stem cells culture system. The effect of increasing storage modulus of scaffold on adipose stem cell fate is currently under investigation.
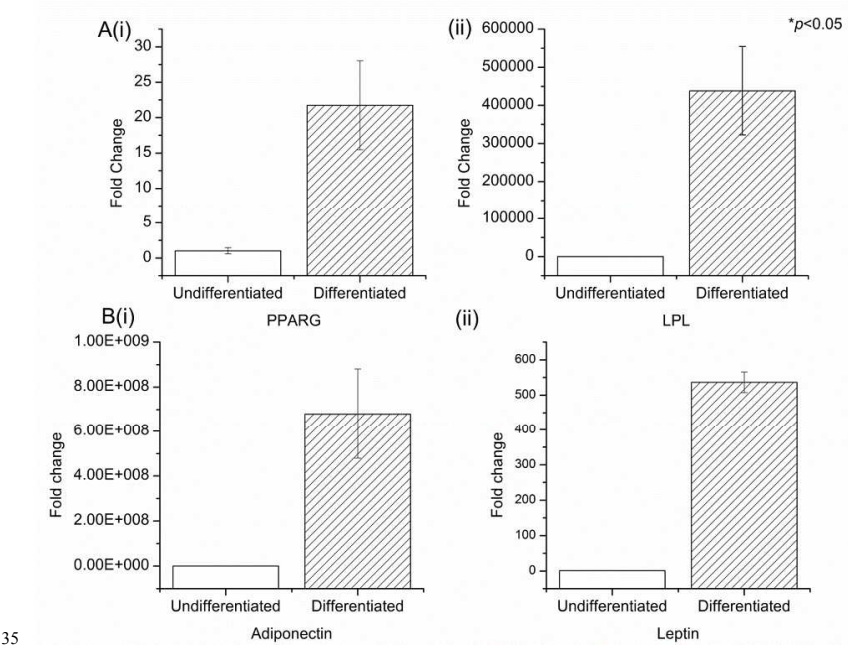

Fig. 10 PCR results for ASCs cultured in the scaffolds with adipogenic supplements compared to undifferentiated ASCs cultured on TCP (control). Fold change values of the samples were shown for (A) early 40 adipogenic markers (i) PPARG and (ii) LPL, and (B) late adipogenic markers (i) adiponectin and (ii) leptin. The upregulation of adipogenic markers suggests that the 3D microenvironment together with the adipogenic supplements led to the differentiation of ASCs into adipocytes $(* \mathrm{p}<0.05, \mathrm{n}=3)$.

\section{${ }_{45}$ Conclusions}

In this study, a novel class of 3D macroporous hydroxypropyl cellulosic scaffolds were developed by UV polymerizing MA conjugated HPC at its biphasic phase. The scaffolds exhibited high swelling ratio, biodegradability, cytocompatibility, and 50 mechanical integrity similar to that of soft tissue in particularly adipose tissue. The pore structure of HPC-MA scaffolds was highly interconnected as a result of the use of phase separation technique followed by lyophilisation. By applying the same principle, macroporous scaffolds can be prepared using other 55 responsive polymers that can form colloidal system induced by environmental stimuli such as temperature and $\mathrm{pH}$ change. The HPC-MA scaffolds promoted ASC infiltration, proliferation and adipogenesis. Hence, these interconnected macroporous hydrogels are promising 3D in vitro adipocyte culture systems 60 that can be used for studying tissue-inherent interactions such as $3 \mathrm{D}$ cell-matrix interactions.

\section{Acknowledgements}

This work was funded by Australia Research Council (ARC) ${ }_{65}$ Discovery Project Grants DP120102570 and Singapore Ministry of Education AcRF Tier 2 ARC16/11. This work was performed in part at the Melbourne Centre for Nanofabrication, an initiative funded jointly by the Commonwealth of Australia and the Victorian government. The authors acknowledge the facilities, 70 and the scientific and technical assistance, of the Australian Microscopy \& Microanalysis Research Facility at the RMIT Microscopy \& Microanalysis Facility, at RMIT University.

\section{Notes and references}


${ }^{a}$ Department of Chemical Engineering, Monash University, Australia. Email:siew.hoo@monash.edu.

${ }^{b}$ MicroNanophysics Research Laboratory, School of Applied Science, RMIT University, Australia. Tel: +6139925 2660. Email:

5 peggy.chan@rmit.edu.au

${ }^{c}$ Melbourne Centre for Nanofabrication, Clayton, Australia

${ }^{d}$ School of Materials Science and Engineering, Nanyang Technological University, Singapore.Fax: +656790 908. Tel: +656513 8166. Email: cleochoong@ntu.edu.sg

$10^{e}$ ARC Centre of Excellence for Electromaterials Science, Intelligent Polymer Research Institute, AIIM facility University of Wollongong, Australia.Email:zyue@uow.edu.au

${ }^{f}$ Department of Mechanical and Aerospace Engineering, Monash University, Australia.Email: jing.fu@monash.edu

${ }_{15}{ }^{g}$ School of Chemical \& Biomedical Engineering, Nanyang Technological University, Singapore.Email: TYTan@ntu.edu.sg

$\dagger$ Electronic Supplementary Information (ESI) available: [details of any supplementary information available should be included here]. See DOI: $10.1039 / \mathrm{b} 000000 \mathrm{x} /$

20

1. P. Bauer-Kreisel, A. Goepferich and T. Blunk, Advanced drug delivery reviews, 2010, 62, 798-813.

2. M. L. Moya, M. H. Cheng, J. J. Huang, M. E. Francis-Sedlak, S. W. Kao, E. C. Opara and E. M. Brey, Biomaterials, 2010, 31, 2816$25 \quad 2826$.

3. E. Thian, J. Huang, M. Vickers, S. Best, Z. Barber and W. Bonfield, Journal of Materials Science, 2006, 41, 709-717.

4. S. Q. Liu, R. Tay, M. Khan, P. L. Rachel Ee, J. L. Hedrick and Y. Y. Yang, Soft Matter, 2010, 6, 67-81.

30 5. C. T. Gomillion and K. J. L. Burg, in Comprehensive Biomaterials, ed. D. Editor-in-Chief: Paul, Elsevier, Oxford, 2011, pp. 529-539.

6. E. Sachlos and J. T. Czernuszka, European cells \& materials, 2003, 5, 29-39; discussion 39-40.

7. T. B. Woodfield, J. Malda, J. de Wijn, F. Peters, J. Riesle and C. A.

35 van Blitterswijk, Biomaterials, 2004, 25, 4149-4161.

8. R. A. Marklein and J. A. Burdick, Adv Mater, 2010, 22, 175-189.

9. L. E. Flynn, Biomaterials, 2010, 31, 4715-4724.

10. I. Levental, P. C. Georges and P. A. Janmey, Soft Matter, 2007, 3, 299-306.

40 11. J. M. Gimble, A. J. Katz and B. A. Bunnell, Circulation research, 2007, 100, 1249-1260.

12. B. Lindroos, R. Suuronen and S. Miettinen, Stem cell reviews, 2011, 7, 269-291.

13. H. Mizuno, Journal of Nihon Medical School $=$ Nihon Ika Daigaku zasshi, 2009, 76, 56-66.

14. P. A. Zuk, M. Zhu, P. Ashjian, D. A. De Ugarte, J. I. Huang, H. Mizuno, Z. C. Alfonso, J. K. Fraser, P. Benhaim and M. H. Hedrick, Molecular biology of the cell, 2002, 13, 4279-4295.

15. B. Galateanu, S. Dinescu, A. Cimpean, A. Dinischiotu and M.

50 Costache, International Journal of Molecular Sciences, 2012, 13, 15881-15900.

16. G. L, K.-V. N, B. K and B. A, Folia Biologica 2011, 57, 47-56.

17. L. Flynn and K. A. Woodhouse, Organogenesis, 2008, 4, 228-235.

18. F. J. O'Brien, B. A. Harley, I. V. Yannas and L. J. Gibson, Biomaterials, 2005, 26, 433-441.

19. S. H. Oh, I. K. Park, J. M. Kim and J. H. Lee, Biomaterials, 2007, 28 , 1664-1671.

20. M. Sabir, X. Xu and L. Li, Journal of Materials Science, 2009, 44, 5713-5724.

60 21. B. Subia, J. Kundu and S. C. Kundu, Tissue Engineering, 2010, 524.
22. Y. Ikada, Tissue Engineering: Fundamentals and Applications, Interface Science and Technology, Elsevier, 2006.

23. J. L. Drury and D. J. Mooney, Biomaterials, 2003, 24, 4337-4351.

24. Q. Cai, J. Yang, J. Bei and S. Wang, Biomaterials, 2002, 23, $4483-$ 654492.

25. N. Soykeabkaew, C. Sian, S. Gea, T. Nishino and T. Peijs, Cellulose, 2009, 16, 435-444.

26. Z. Yue, F. Wen, S. Gao, M. Y. Ang, P. K. Pallathadka, L. Liu and H. Yu, Biomaterials, 2010, 31, 8141-8152.

70 27. M. A. Hussain, Journal of Polymer Science Part A: Polymer Chemistry, 2008, 46, 747-752.

28. J. M. Pachence, M. P. Bohrer and J. Kohn, in Principles of Tissue Engineering (Third Edition), eds. L. Robert, L. Robert, R. L. Joseph VacantiA2 - Robert Lanza and V. Joseph, Academic Press, 75 Burlington, 2007, pp. 323-339.

29. A. Al-Abboodi, J. Fu, P. M. Doran and P. P. Y. Chan, Biotechnology and Bioengineering, 2013, 110, 318-326.

30. W. Dong, H. Li, M. Chen, Z. Ni, J. Zhao, H. Yang and P. Gijsman, $J$ Polym Res, 2011, 18, 1239-1247.

80 31. G. D. Nicodemus and S. J. Bryant, Tissue engineering. Part B, Reviews, 2008, 14, 149-165.

32. R. S. Benson, Nuclear Instruments and Methods in Physics Research Section B: Beam Interactions with Materials and Atoms, 2002, 191, $752-757$.

85 33. C. G. Williams, A. N. Malik, T. K. Kim, P. N. Manson and J. H. Elisseeff, Biomaterials, 2005, 26, 1211-1218.

34. L.-S. Wang, J. E. Chung, P. Pui-Yik Chan and M. Kurisawa, Biomaterials, 2010, 31, 1148-1157.

35. M. Davidovich-Pinhas and H. Bianco-Peled, Carbohydrate Polymers, 2010, 79, 1020-1027.

36. F. Lee, J. E. Chung and M. Kurisawa, Journal of Controlled Release, 2009, 134, 186-193.

37. W.-F. Lee and W.-H. Chiang, Journal of Applied Polymer Science, 2004, 91, 2135-2142.

95 38. D. Singh, D. Kuckling, V. Koul, V. Choudhary, H.-J. Adler and A. K. Dinda, European Polymer Journal, 2008, 44, 2962-2970.

39. D. Wang, D. J. T. Hill, F. Rasoul and A. K. Whittaker, Radiation Physics and Chemistry, 2011, 80, 207-212.

40. W. L. K. Chen and C. A. Simmons, Advanced drug delivery reviews, 2011, 63, 269-276.

41. G. C. Reilly and A. J. Engler, Journal of biomechanics, 2010, 43, 5562.

42. L.-S. Wang, J. Boulaire, P. P. Y. Chan, J. E. Chung and M. Kurisawa, Biomaterials, 2010, 31, 8608-8616.

105 43. L. S. Wang, P. Y. Chow, T. T. Phan, I. J. Lim and Y. Y. Yang, Advanced Functional Materials, 2006, 16, 1171-1178.

44. B. G. Kabra, S. H. Gehrke and R. J. Spontak, Macromolecules, 1998, 31, 2166-2173.

45. V. Karageorgiou and D. Kaplan, Biomaterials, 2005, 26, 5474-5491.

110 46. J. Ma, C. Wang and K. W. Peng, Biomaterials, 2003, 24, 3505-3510.

47. R. M. Pilliar, M. J. Filiaggi, J. D. Wells, M. D. Grynpas and R. A. Kandel, Biomaterials, 2001, 22, 963-972.

48. E. Romero and P. Simms, Geotech Geol Eng, 2008, 26, 705-727.

49. Ž. Zuzana, G. Eva and P. Willi, Processing and Application of 115 Ceramics, 2008, 2, 1-8. 
50. Q. Liu, Y. Li, S. Shen and Z. Shanshan, Materials Chemistry and Physics, 2011, 125, 315-318.

51. R. van Dijkhuizen-Radersma, L. Moroni, A. v. Apeldoorn, Z. Zhang and D. Grijpma, in Tissue Engineering, eds. B. Clemens van, T.

5 Peter, L. Anders, H. Jeffrey, F. W. David, C. Ranieri, D. d. B. Joost, P. T. A. L. J. H. D. F. W. R. C. J. D. d. B. Jérôme SohierA2 Clemens van Blitterswijk and S. Jérôme, Academic Press, Burlington, 2008, pp. 193-221.

52. M. Märtson, J. Viljanto, T. Hurme, P. Laippala and P. Saukko, 10 Biomaterials, 1999, 20, 1989-1995.

53. K. S. Anseth, V. R. Shastri and R. Langer, Nat Biotech, 1999, 17, 156-159.

54. L. S. Nair and C. T. Laurencin, Progress in Polymer Science, 2007, 32, $762-798$.

15 55. C. B. Hutson, J. W. Nichol, H. Aubin, H. Bae, S. Yamanlar, S. AlHaque, S. T. Koshy and A. Khademhosseini, Tissue engineering. Part A, 2011, 17, 1713-1723.

56. Q. Li, J. Wang, S. Shahani, D. D. N. Sun, B. Sharma, J. H. Elisseeff and K. W. Leong, Biomaterials, 2006, 27, 1027-1034.

20 57. A. J. García and D. Boettiger, Biomaterials, 1999, 20, 2427-2433.

58. C. Chang and L. Zhang, Carbohydrate Polymers, 2011, 84, 40-53.

59. Y. Ke, Y. J. Wang, L. Ren, Q. C. Zhao and W. Huang, Acta Biomaterialia, 2010, 6, 1329-1336.

60. Y. Chen and L. Liu, Advanced drug delivery reviews, 2012, 64, 64025665 .

61. H. Li, J. R. Friend and L. Y. Yeo, Biomaterials, 2007, 28, 4098-4104.

62. A. G. Cristancho and M. A. Lazar, Nature reviews. Molecular cell biology, 2011, 12, 722-734.

63. C. Yu, J. Bianco, C. Brown, L. Fuetterer, J. F. Watkins, A. Samani and L. E. Flynn, Biomaterials, 2013, 34, 3290-3302.

64. K. Comley and N. A. Fleck, International Journal of Solids and Structures, 2010, 47, 2982-2990.

65. D. H. Stacey, S. E. Hanson, G. Lahvis, K. A. Gutowski and K. S. Masters, Tissue engineering. Part A, 2009, 15, 3389-3399.

35 66. F. Guilak, D. M. Cohen, B. T. Estes, J. M. Gimble, W. Liedtke and C. S. Chen, Cell stem cell, 2009, 5, 17-26.

67. N. Huebsch, P. R. Arany, A. S. Mao, D. Shvartsman, O. A. Ali, S. A. Bencherif, J. Rivera-Feliciano and D. J. Mooney, Nat Mater, 2010, 9, 518-526.

40 68. M. P. Lutolf, P. M. Gilbert and H. M. Blau, Nature, 2009, 462, $433-$ 441.

69. K. A. Kilian, B. Bugarija, B. T. Lahn and M. Mrksich, Proceedings of the National Academy of Sciences of the United States of America, 2010, 107, 4872-4877.

45 70. R. McBeath, D. M. Pirone, C. M. Nelson, K. Bhadriraju and C. S. Chen, Developmental Cell, 2004, 6, 483-495.

71. S. A. Ruiz and C. S. Chen, Stem Cells, 2008, 26, 2921-2927.

50 
Graphical Abstract

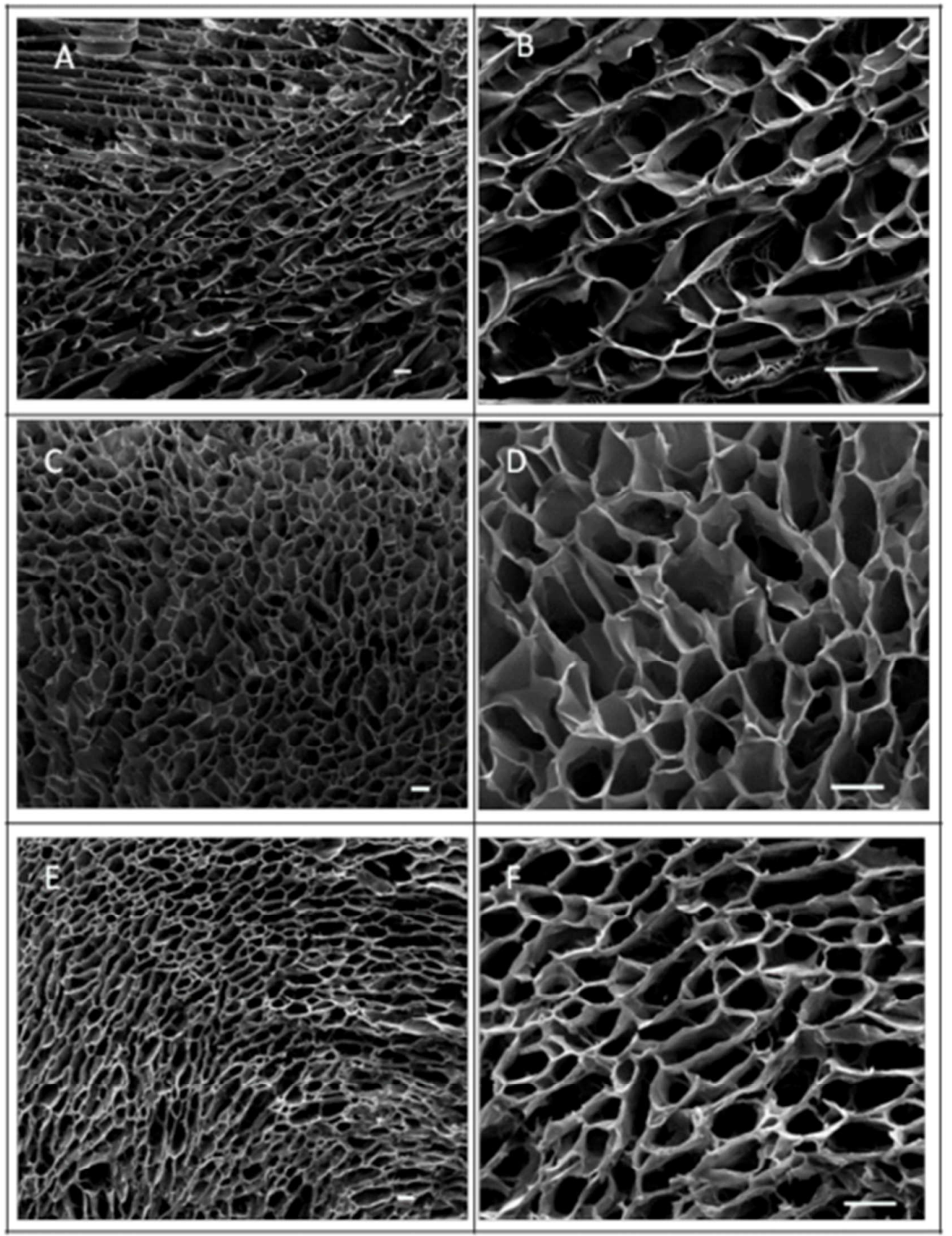

This study describes the preparation and characterization of a biodegradable and porous 3D hydrogel constructed from hydroxypropyl cellulose, modified with bifunctional hydroxpropyl cellulose methacrylate, for adipose tissue engineering applications. 


\begin{tabular}{lll}
\hline Gene & $\mathbf{5}$ ' to 3' Sequence (sense) & $\mathbf{5}$ ' to 3' Sequence (antisense) \\
\hline GAPDH & CCCCTTCATTGACCTCAACTACA & TTGCTGATGATCTTGAGGCTGT \\
PPARG & CTCCTATTGACCCAGAAAGC & GTAGAGCTGAGTCTTCTCAG \\
LPL & ATGGAGAGCAAAGCCCTGCTC & GTTAGGTCCAGCTGGATCGAG \\
Leptin & GTGCC-TATCCAGAAAGTCCAG & TCAGCATTCAGGGCTAACA TC \\
Adiponectin CATGACCAGGAAACCACGACT & TGAATGCTGAGCGGTAT
\end{tabular}

Table 1. PCR primers $200 \times 81 \mathrm{~mm}(72 \times 72 \mathrm{DPI})$ 


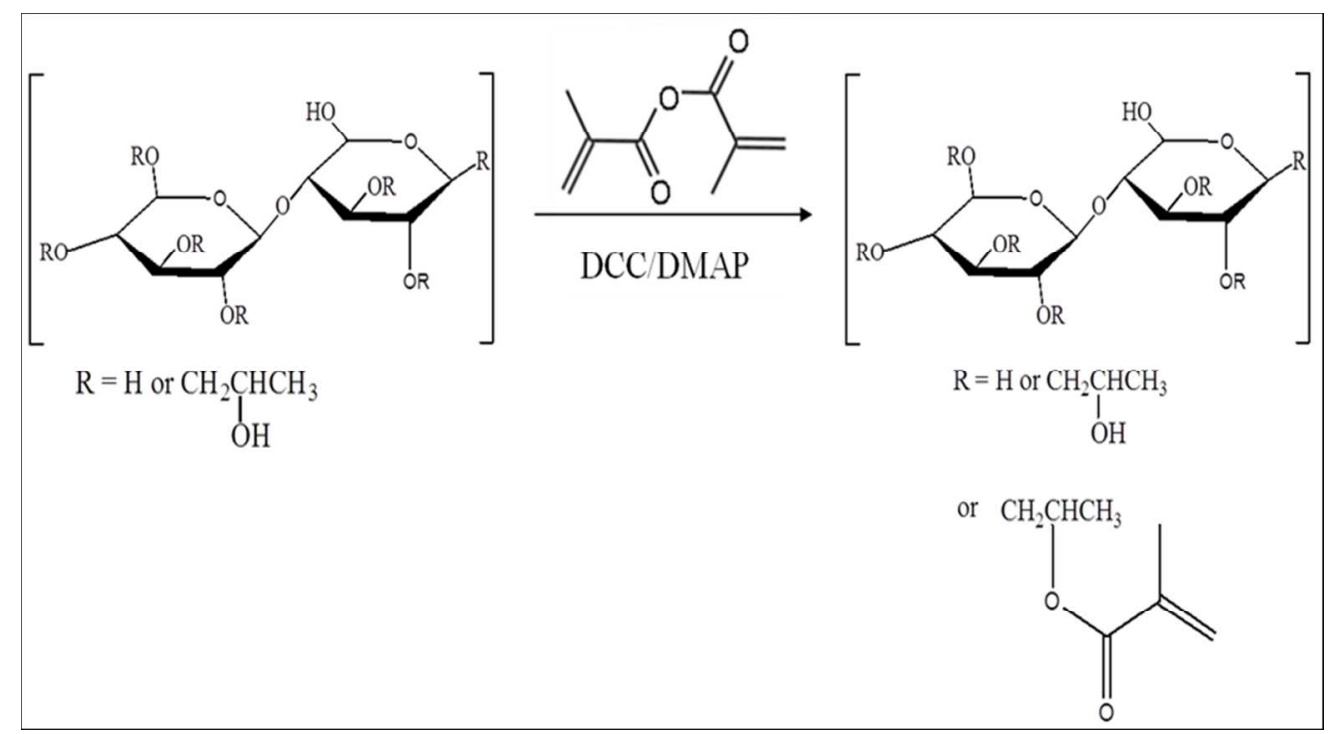

Fig. 1a Synthesis scheme of HPC-MA $256 \times 127 \mathrm{~mm}(135 \times 150 \mathrm{DPI})$ 


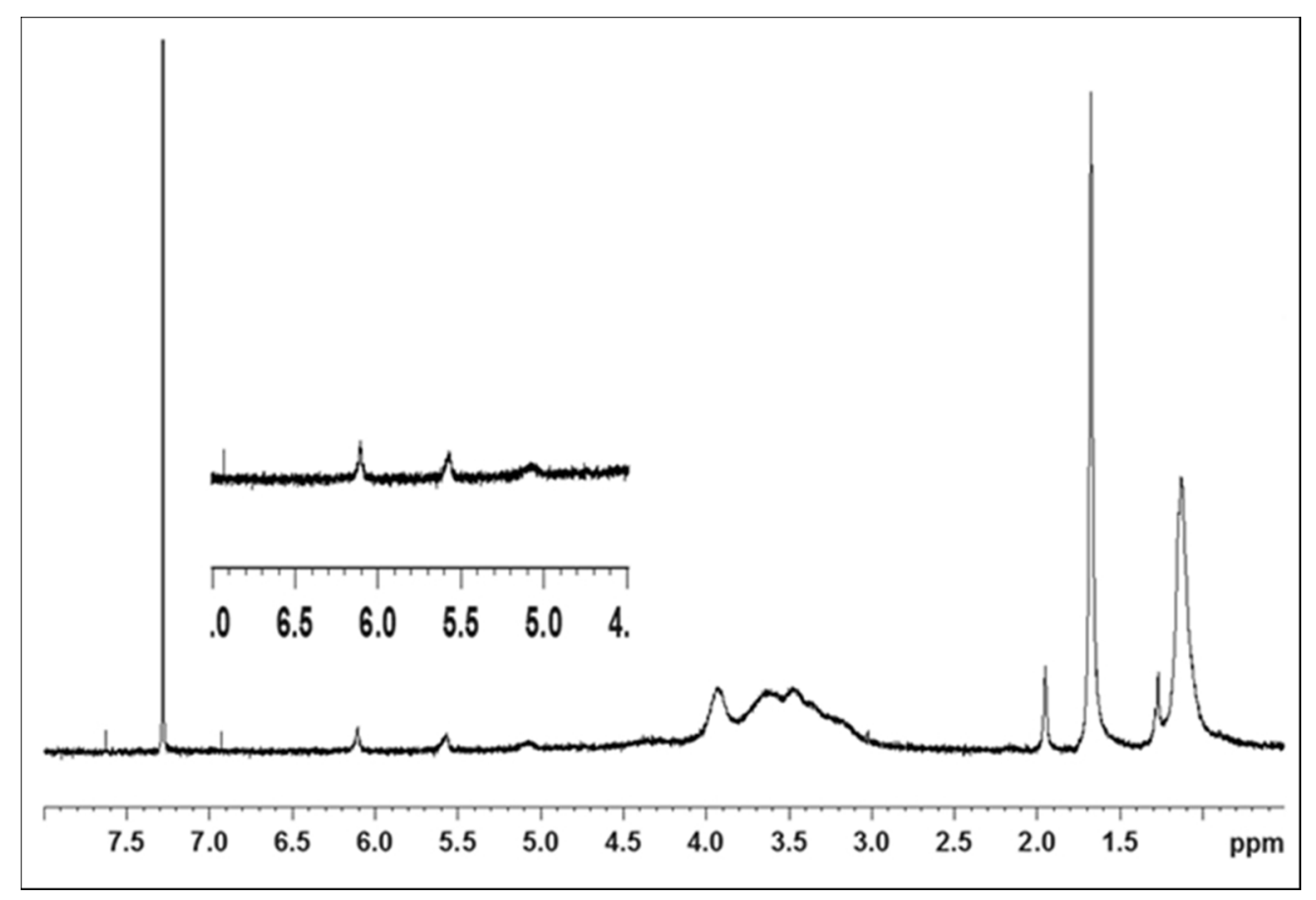

Fig. 1b NMR of HPC-MA in $\mathrm{CDCl}_{3}$ $164 \times 112 \mathrm{~mm}(150 \times 150 \mathrm{DPI})$ 


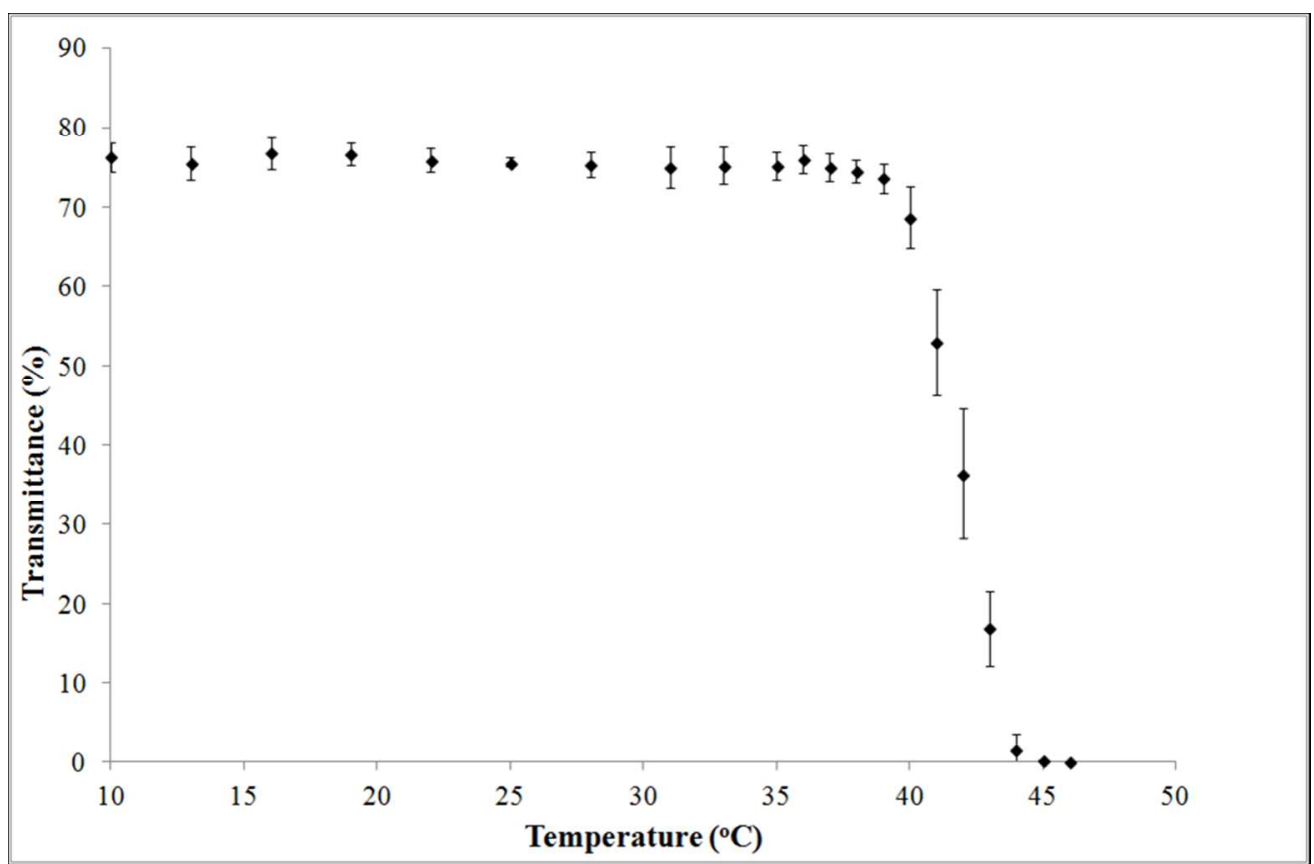

Fig. 1c Turbidimetry measurement for HPC-MA-10 \%. The data are shown as mean values with standard deviation as error bars in the form of mean value \pm standard deviation. $260 \times 170 \mathrm{~mm}(96 \times 96 \mathrm{DPI})$ 


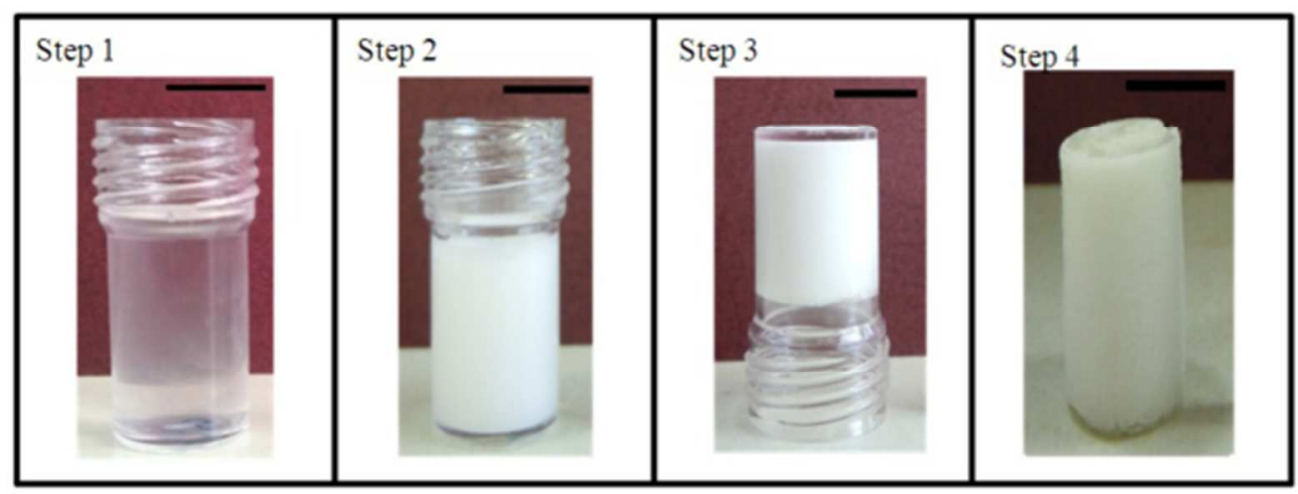

Fig. 1d Preparation of HPC-MA scaffold (scale bar $1.0 \mathrm{~cm}$ ) from (Step 1) homogenous solution of HPC-MA-10 $\%$ at room temperature, to (Step 2) phase separated colloidal fluid at $\sim 45^{\circ} \mathrm{C}$, (Step 3) crosslinked heterogeneous gel at room temperature and (Step 4) freeze-dried scaffold. $222 \times 83 \mathrm{~mm}(72 \times 72 \mathrm{DPI})$ 

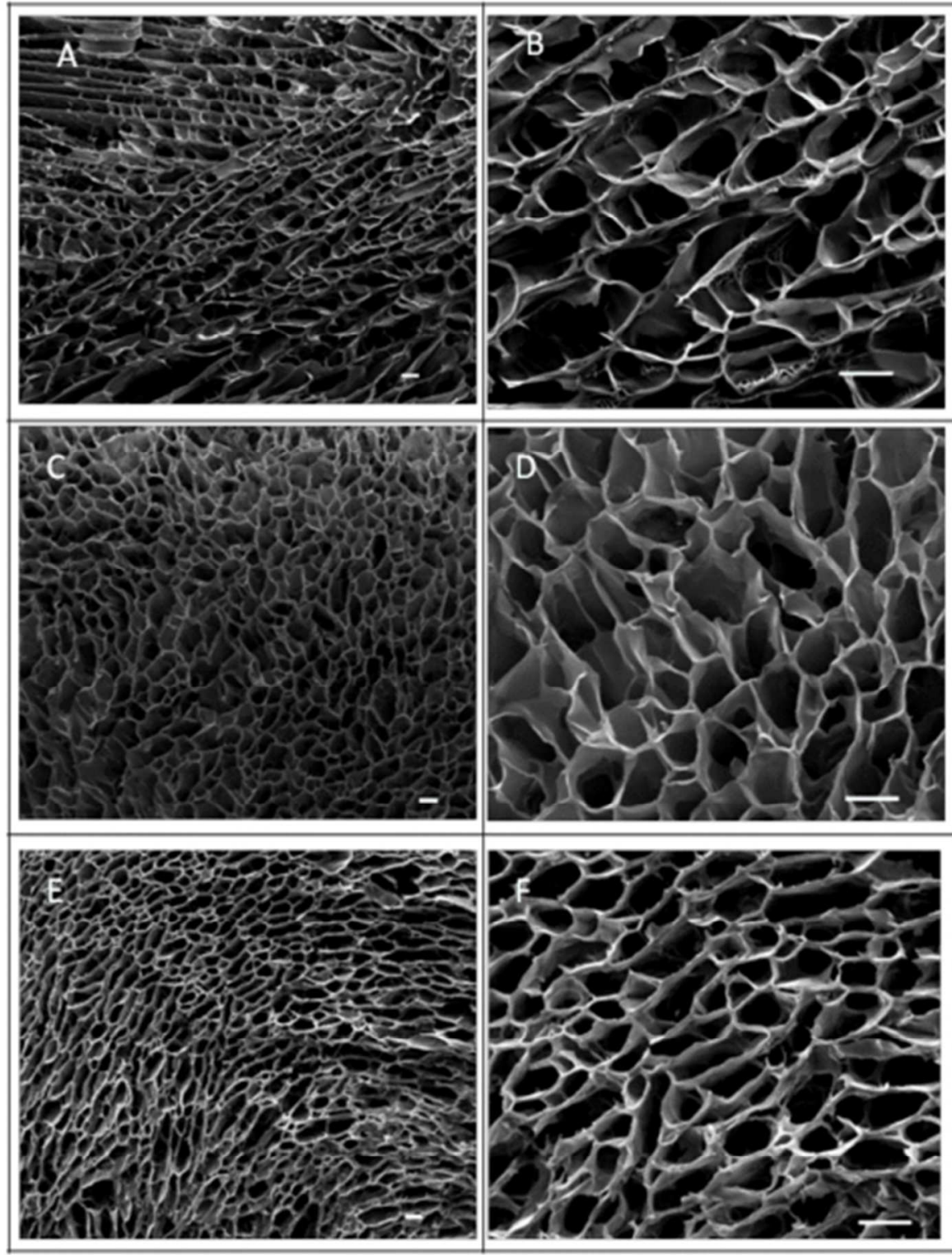

Fig. 3 Pore size and morphology of HPC-MA scaffolds. (A) and (B), (C) and (D), (E) and (F) are representative cross-sectional SEM of lyophilised HPC-MA-10 wt\%, 15 wt\% and 20 wt $\%$, at low and high magnification (scale bar $100 \mu \mathrm{m}$ ), respectively.micrographs $172 \times 225 \mathrm{~mm}(72 \times 72 \mathrm{DPI})$ 


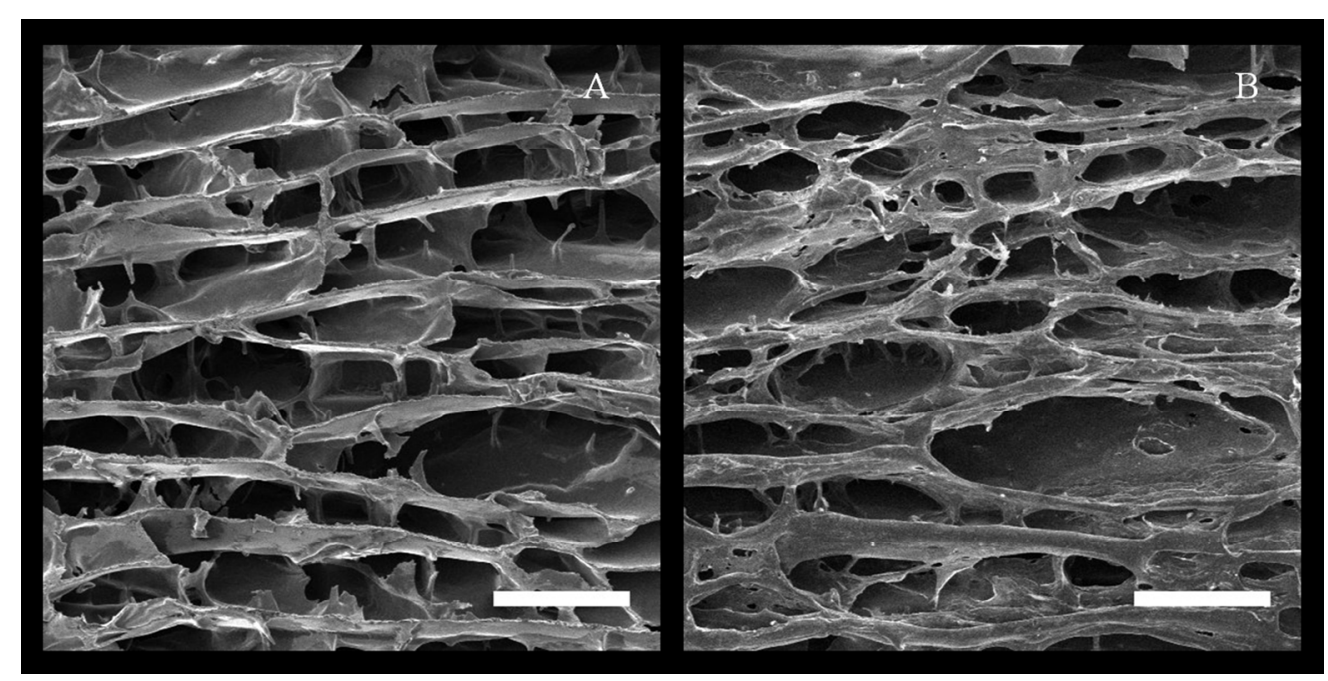

Fig. 4a FIB/SEM of HPC-MA-10 wt\% (scale bar $100 \mu \mathrm{m}$ ), top view SEM image of the scaffold before milling (A), after a layer of approximately $50 \mu \mathrm{m}$ in thickness milled off by FIB (B) $227 \times 114 \mathrm{~mm}(150 \times 150 \mathrm{DPI})$ 


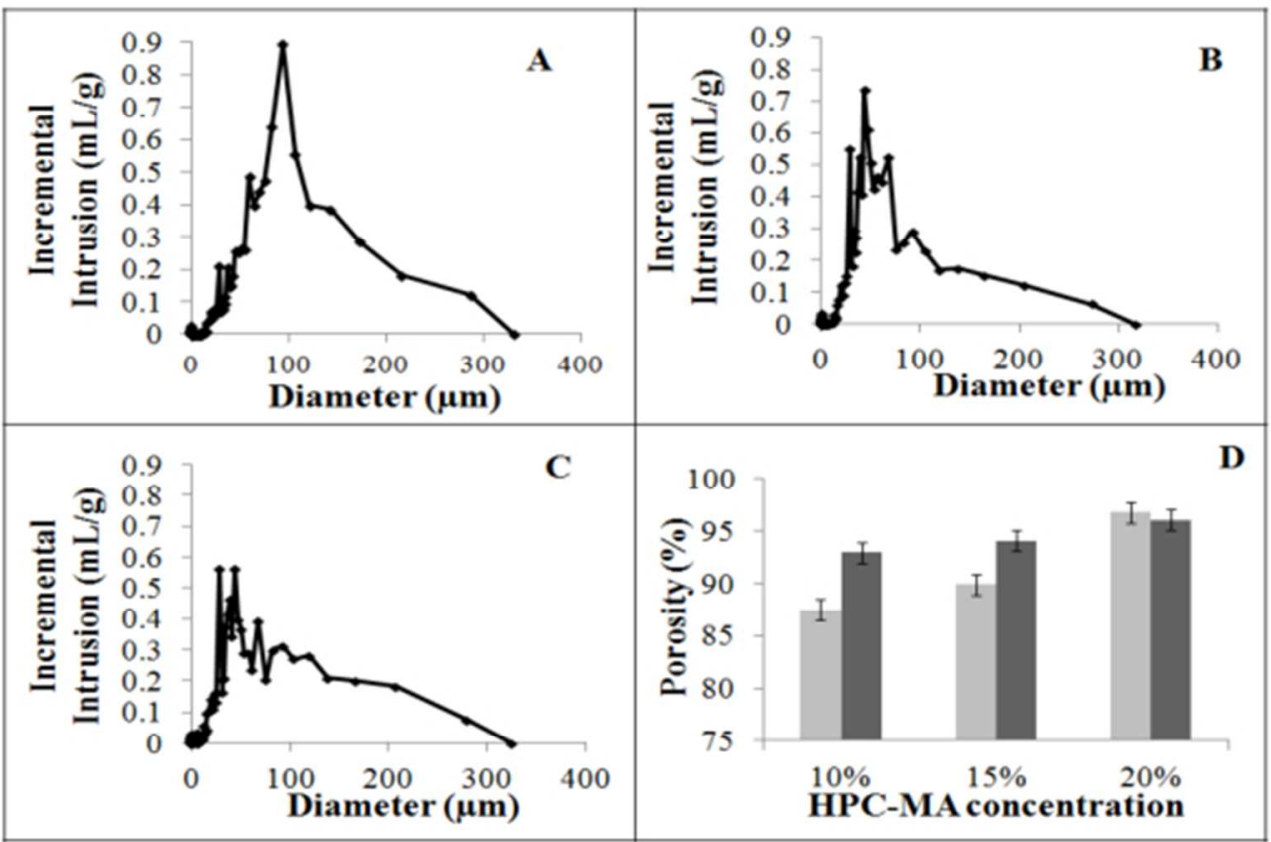

Fig. 4b Pore size distribution of HPC-MA-0.35-10 wt\% (A), 15 wt\% (B) and 20 wt\% (C); Porosity (grey square) and interconnected porosity (black square) of HPC-MA scaffold (D). The data are shown as mean values with standard deviation as error bars in the form of mean value \pm standard deviation. 


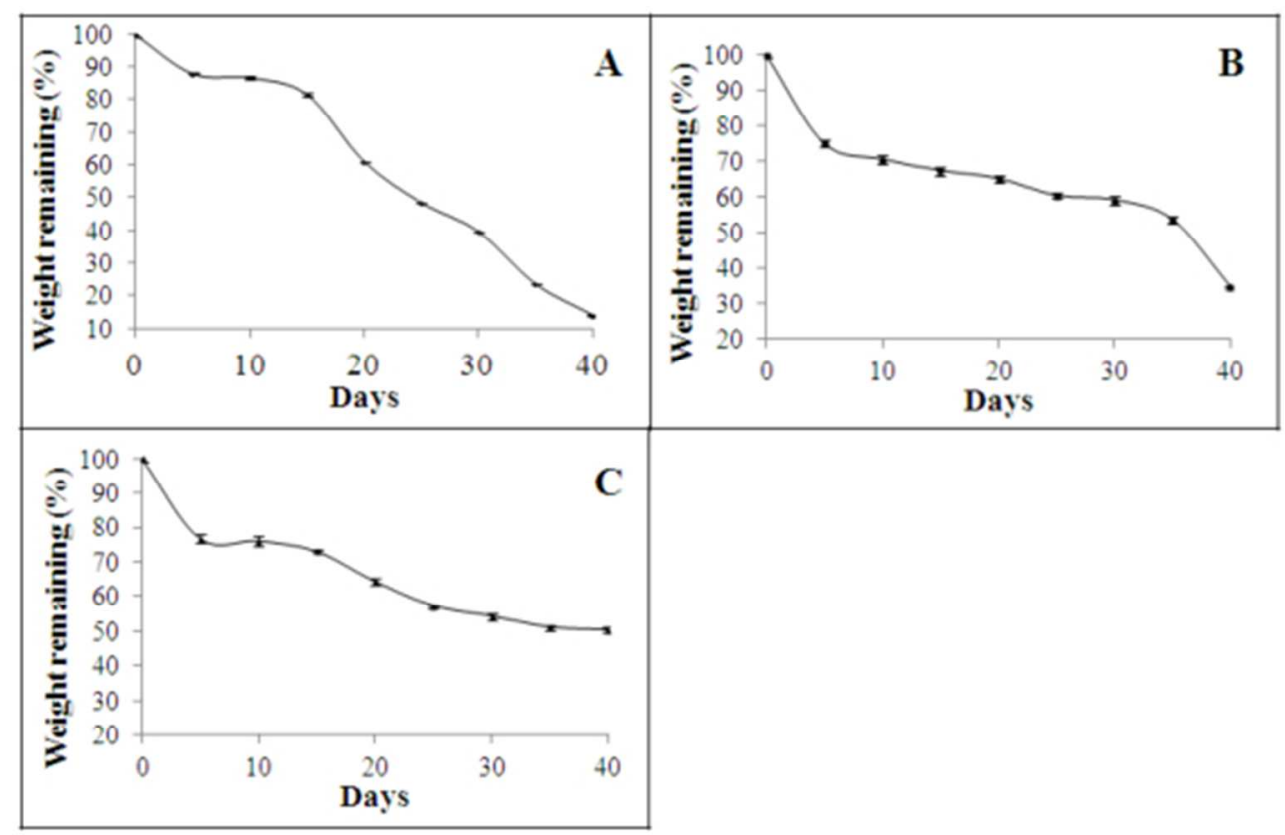

Fig. 5 Degradation profile of HPC-MA-10 wt\% (A), 15 wt\% (B) and $20 w t \%(C)$. The data are shown as mean values with standard deviation as error bars in the form of mean value \pm standard deviation, and the standard deviations appear to be small.

$203 \times 134 \mathrm{~mm}(72 \times 72 \mathrm{DPI})$ 


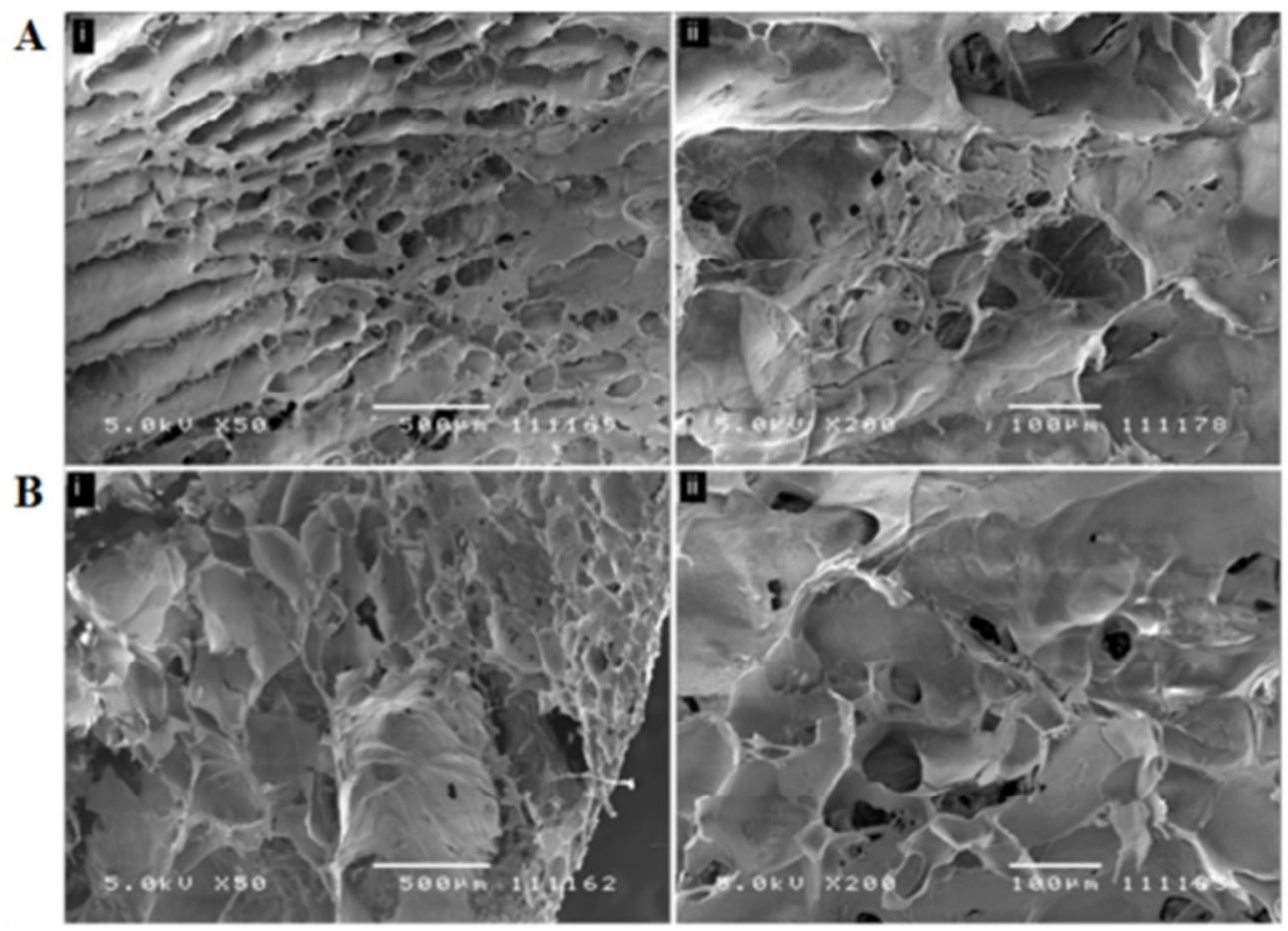

Fig. 6 SEM micrographs illustrating the presence of ASCs on the (A) 20 surface and (B) cross-section of Day 14 cell cultured HPC-MA-10 wt\% scaffolds at (i) 50X and (ii) 200X magnifications. $181 \times 131 \mathrm{~mm}(72 \times 72 \mathrm{DPI})$ 


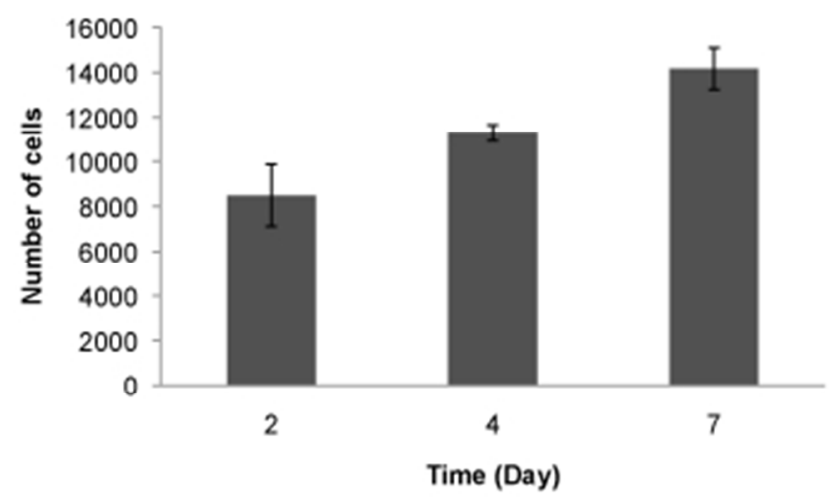

Fig. 7 Number of ASCs in the HPC-MA-10 wt\% scaffolds over a period of one week $190 \times 133 \mathrm{~mm}(72 \times 72 \mathrm{DPI})$ 


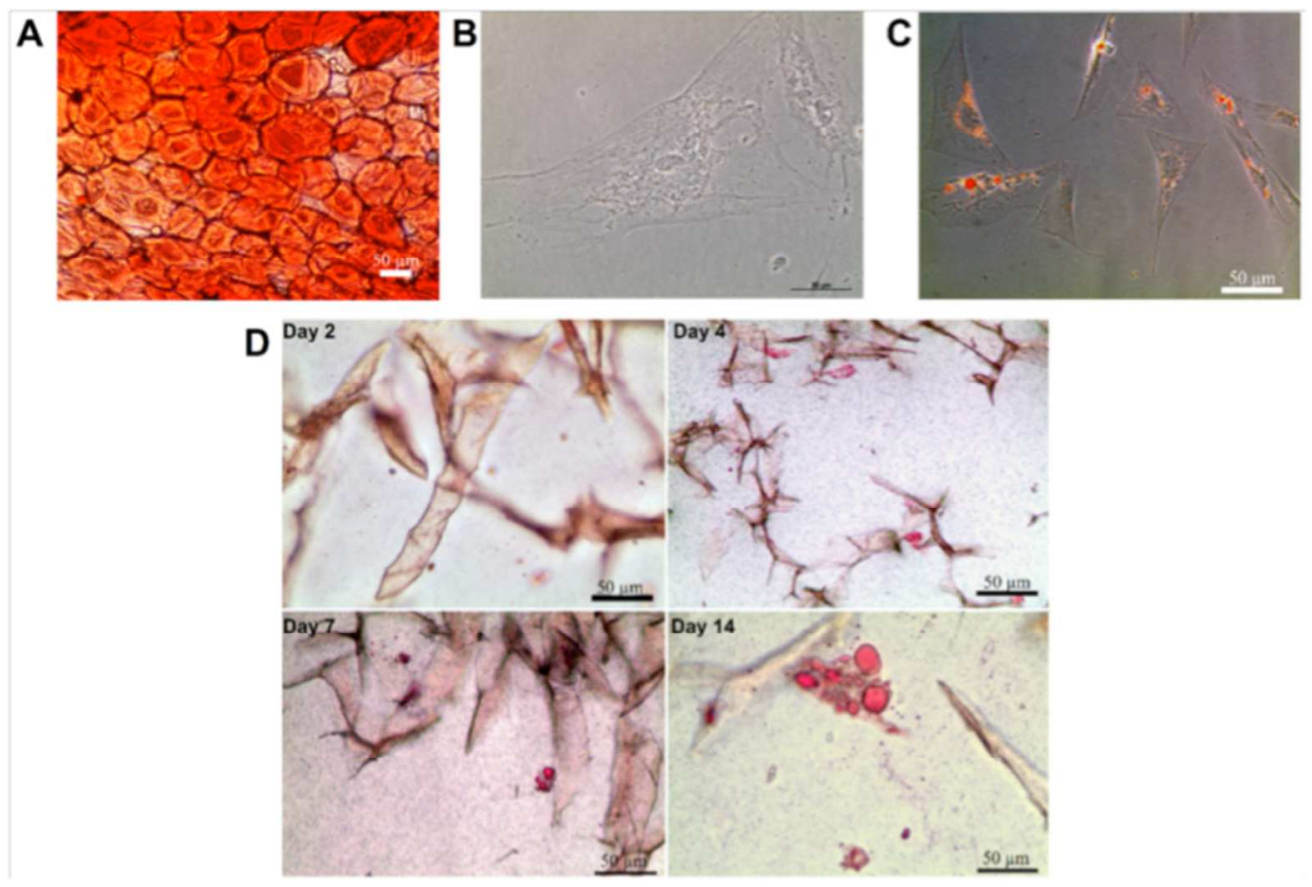

Fig. 8 Oil Red $O$ staining of the lipid droplets of $(A)$ fat tissue, (B) ASCs grown on 2D TCP without adipogenic supplement, (C) ASCs grown on 2D TCP with adipogenic supplment (Day 14), and (D) ASCs grown in the 3D HPC-MA-10 wt\% scaffold over a period of 14 days and lipid droplets were observed to be present from Day 4 onwards. Scale bar $50 \mu \mathrm{m}$ $266 \times 178 \mathrm{~mm}(72 \times 72 \mathrm{DPI})$ 
A

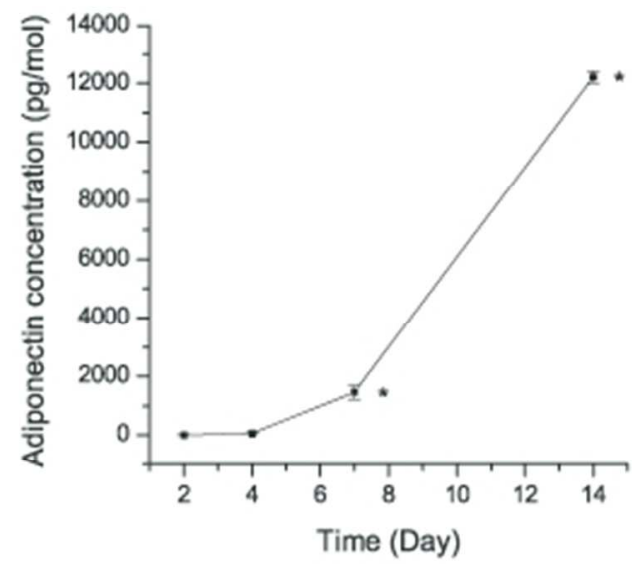

B

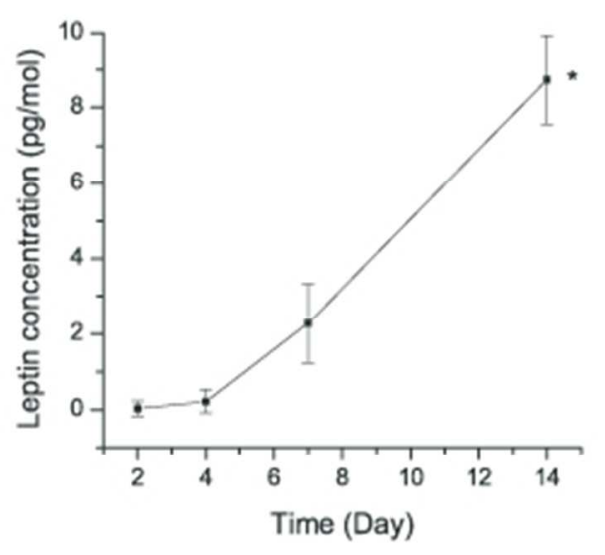

Fig. 9 Amount of (A) adiponectin and (B) leptin released into the medium over a period of 14 days. Both adiponectin and leptin were released from Day 4 onwards, and the amount released increased significantly after 14 days of culture $(* p<0.05, n=3)$. The data are shown as mean values with standard deviation as error bars in the form of mean value \pm standard 5 deviation, and the standard deviations appear to be small.

$190 \times 100 \mathrm{~mm}(72 \times 72 \mathrm{DPI})$ 

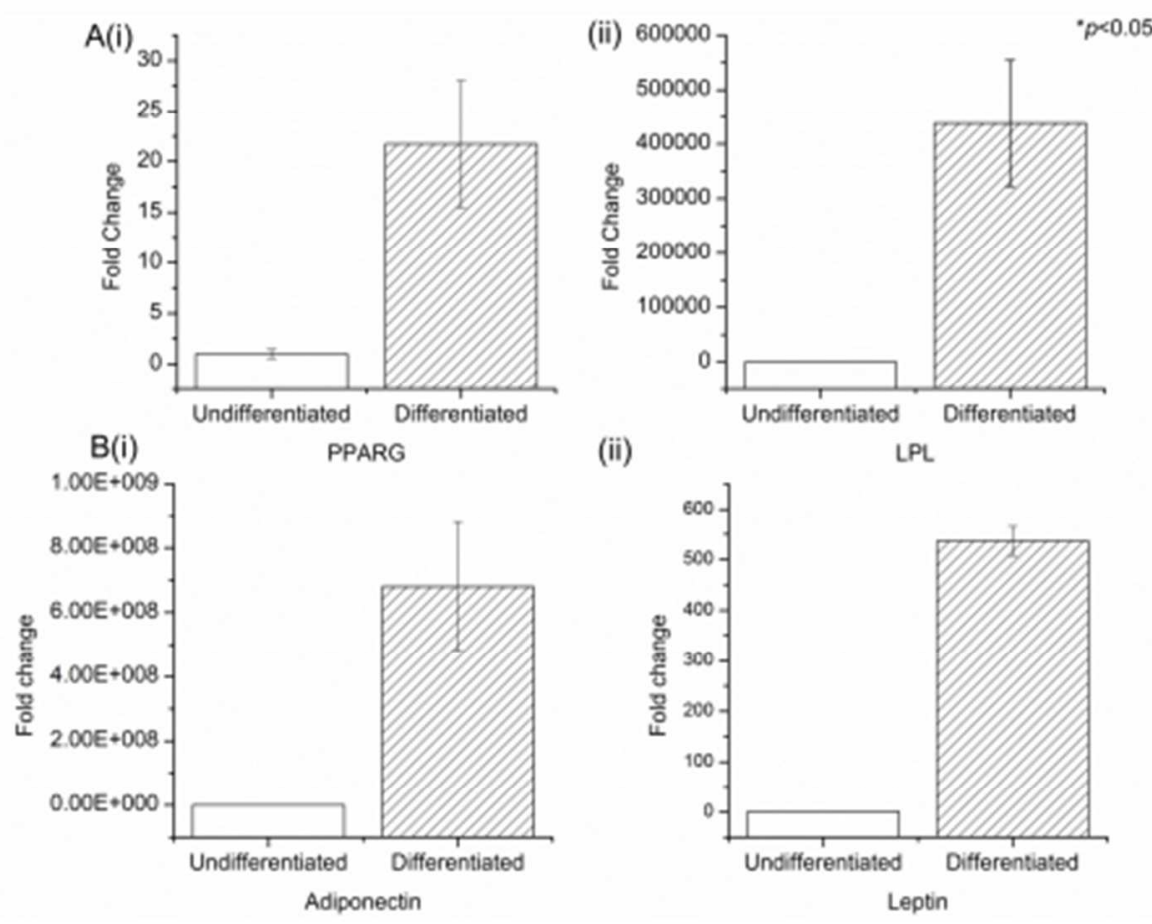

(ii)

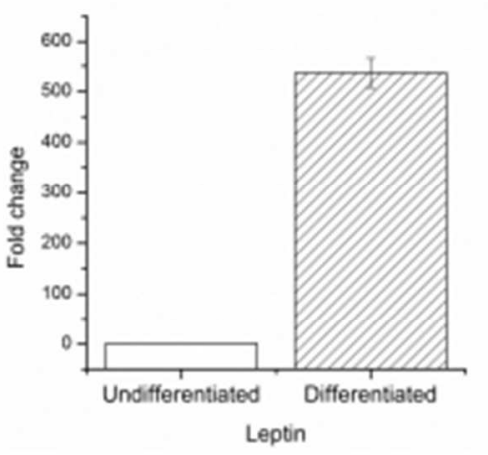

Fig. 10 PCR results for ASCs cultured in the scaffolds with adipogenic supplements compared to undifferentiated ASCs (control). Fold change values of the samples were shown for (A) early adipogenic markers (i) PPARG and (ii) LPL, and (B) late adipogenic markers (i) adiponectin and (ii) leptin. The upregulation of adipogenic markers suggests that the 3D microenvironment together with the adipogenic supplements led to the 40 differentiation of ASCs into adipocytes $(* p<0.05, n=3)$.

$161 \times 127 \mathrm{~mm}(72 \times 72 \mathrm{DPI})$ 